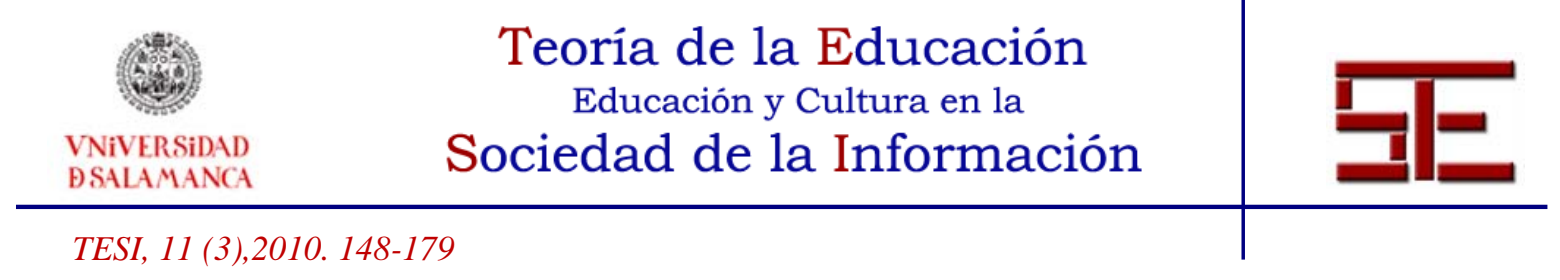

\title{
BUENAS PRÁCTICAS ORGANIZATIVAS PARA LA INTEGRACIÓN DE LAS TIC EN EL SISTEMA EDUCATIVO EXTREMEÑO
}

Resumen:

En el presente trabajo se pretende dar a conocer Buenas Prácticas de tipo organizativo para la integración de las TIC que ha llevado a cabo el Sistema Educativo Extremeño. Para ello, en un primer momento, se ha realizado una revisión teórica sobre el concepto de Buenas Prácticas, estableciendo algunos indicadores que nos permitan identificar Buenas Prácticas en el uso de las TIC en los centros educativos de Primaria y Secundaria, y destacando especialmente aquellos indicadores que hacen referencia a aspectos organizativos del centro y de las aulas. En segundo lugar, se ha efectuado un análisis de la política de integración de las tecnologías que ha llevado a cabo la Junta de Extremadura, enfatizando en la figura del/la Coordinador/a TIC como medida de calidad, así como en las herramientas tecnológicas de gestión del centro y control del aula. Por último, se presentan algunos resultados obtenidos a partir de diversas entrevistas efectuadas a distintos miembros de la Comunidad Educativa de una investigación ${ }^{1}$ mucho más amplia en la que hemos realizado el estudio de casos de centros de Primaria y Secundaria considerados como Buenas Prácticas con TIC.

\section{Palabras clave:}

Buenas prácticas, Tecnologías de la Información y Comunicación (TIC), organización, política educativa, coordinador/a TIC.

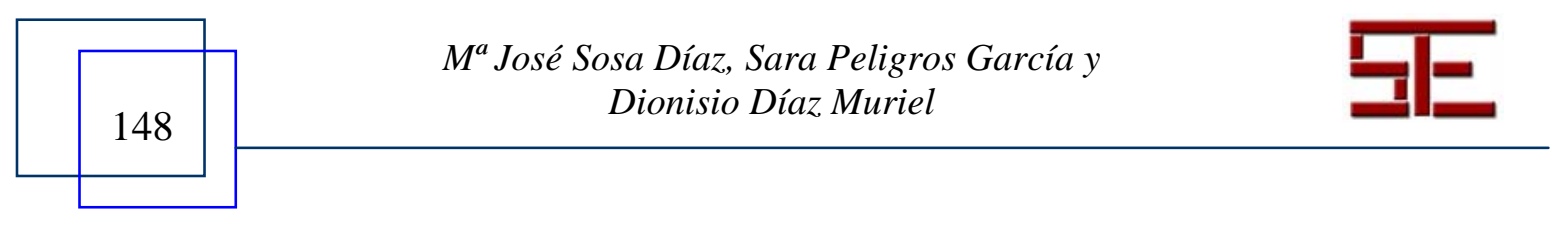




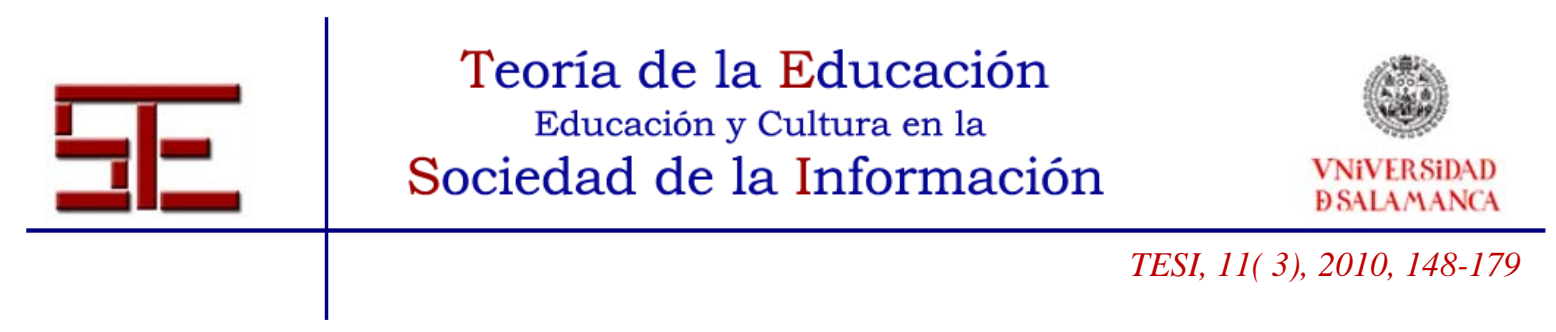

\title{
ORGANIZATIONAL GOOD PRACTICES FOR THE INTEGRATION OF THE ICT IN THE EDUCATION SYSTEM OF EXTREMADURA
}

\begin{abstract}
:
The present paper tries to release some organizational Good Practices for the integration of the ICT's carried out by the Education System in Extremadura. For this, in a first moment, a theoretical review about the concept of Good Practices has been done, establishing some indicators which permit us identify Good Practices regarding the application of the ICT within Primary and Secondary schools, and specially pointing out the indicators that refer to organizational aspects in the educational establishments and classrooms. Secondly, the politics for the integration of New Technologies conducted by Junta de Extremadura are analyzed, emphasizing the figure of the ICT Coordinator as a quality measure, as well as the technological tools for school management and controlling the classes. Finally, we present the results obtained from several interviews that were made to different members of the school community, all in a broader investigation where diverse case studies of Primary and Secondary schools considered as Good Practices with ICT were effectuated.
\end{abstract}

Key words:

Good Practices, New Technologies, ICT, organization, educational politics, ICT coordinator.

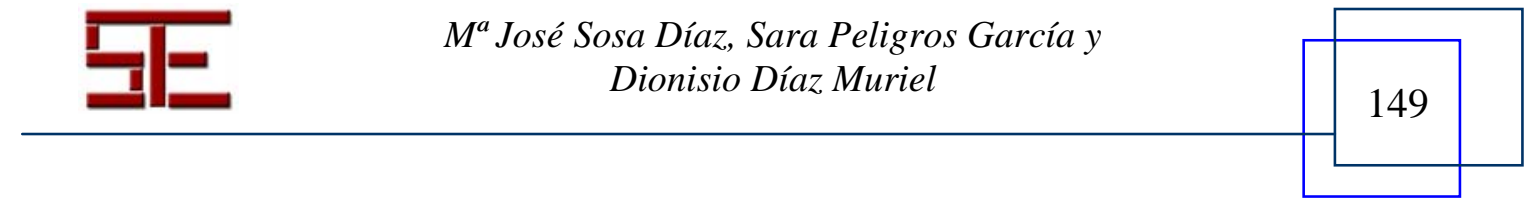




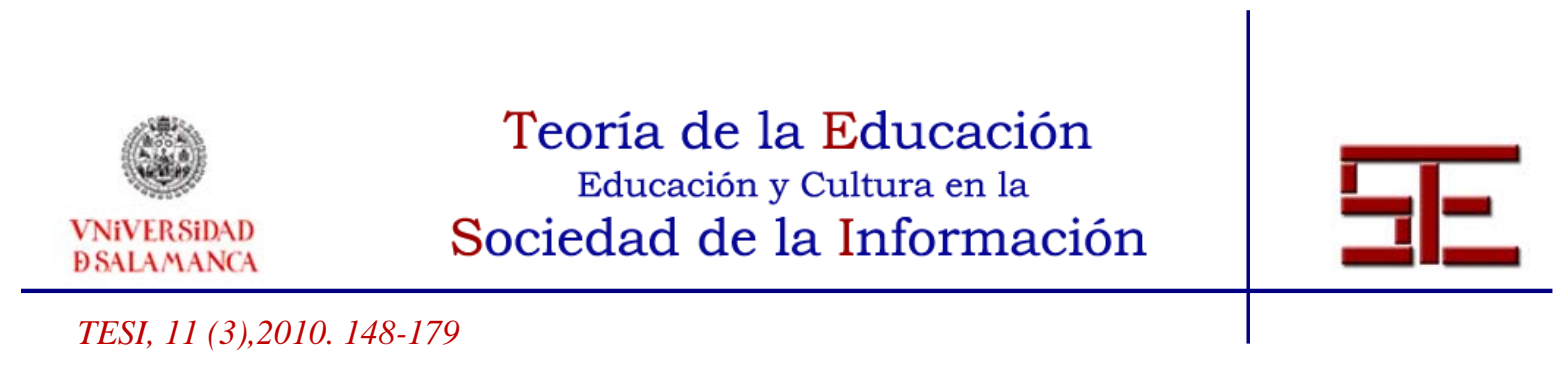

\title{
BUENAS PRÁCTICAS ORGANIZATIVAS PARA LA INTEGRACIÓN DE LAS TIC EN EL SISTEMA EDUCATIVO EXTREMEÑO
}

Fecha de recepción: 20/02/2009; fecha de aceptación: 28/09/2009; fecha de publicación: 28/02/10

\author{
Ma José Sosa Díaz \\ mjosesosa@unex.es \\ Universidad de Extremadura \\ Sara Peligros García \\ speligros@alumnos.unex.es \\ Universidad de Extremadura \\ Dionisio Díaz Muriel \\ didiaz@unex.es \\ Universidad de Extremadura
}

\section{1.- INTRODUCCIÓN}

Es inevitable comenzar haciendo referencia a la relevancia que tienen las Tecnologías de la Información y Comunicación (TIC) en la sociedad actual o, como muchos denominan, la Sociedad del Conocimiento, pues ésta es la principal razón por la que las políticas educativas deben dirigir sus esfuerzos a la integración de las Buenas Prácticas en el sistema educativo.

Ya en la sesión que celebró el Consejo Europeo de 2000 en Lisboa se acordó un nuevo objetivo estratégico de la Unión para la próxima década, a fin de reforzar el empleo, la reforma económica y la cohesión social como parte de una economía basada en el conocimiento. Así pues, se recomendó a todos los Estados miembros de la Unión que garantizaran en todas las escuelas el acceso a Internet y a los recursos multimedia, y que todos los docentes estuvieran formados para un adecuado uso educativo de éstos.

De este modo, la integración de las TIC en la educación se presenta como un reto para todos los sistemas educativos de Europa. En España, desde el traspaso de funciones y servicios en materia educativa, cada una de las Comunidades Autónomas tiene su propio modelo de integración de las TIC en el campo educativo. Aunque evidentemente

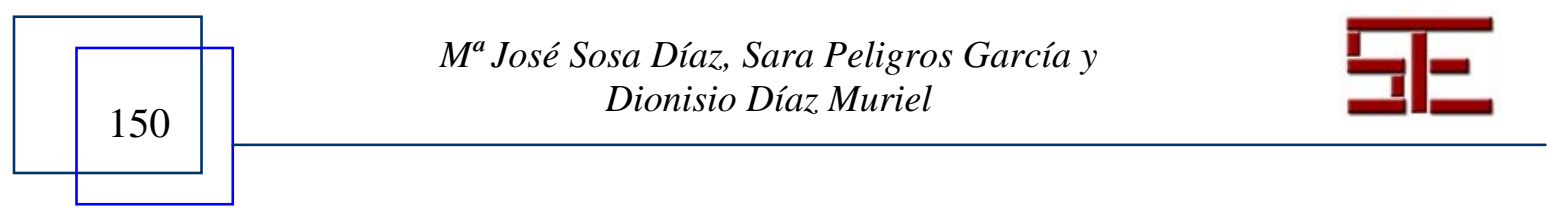




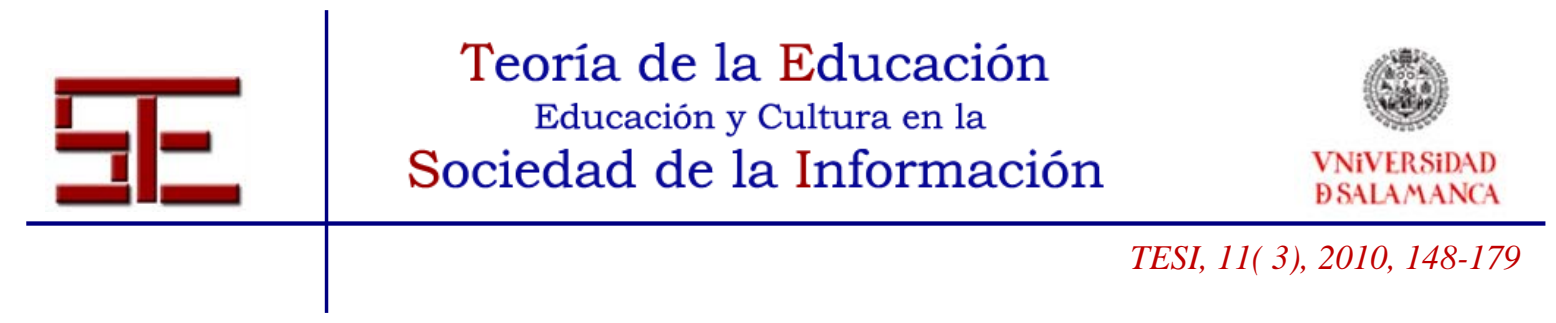

el ritmo de dotación y el alcance de la misma es variable en cada Comunidad, es cierto que la mayoría de las Administraciones han realizado un gran esfuerzo presupuestario y su papel respecto a la integración de las Buenas Prácticas en los centros ha sido decisivo, ya que desde hace algunos años los principales objetivos de las políticas educativas para las distintas autonomías han consistido esencialmente en el equipamiento informático, la formación de los docentes y la creación de materiales curriculares.

Sin embargo, a pesar de la implantación de los equipos informáticos en los centros, de las innumerables ventajas y potencialidades del uso de las Tecnologías de la Comunicación y la Información (TIC) en el ámbito educativo, de la oferta formativa dirigida a los docentes, que resulta en muchas ocasiones deficiente, y del trabajo que hacen algunas Comunidades para el fomento de la creación libre de contenidos digitales, de manera generalizada en la mayoría de los centros aún no se percibe una plena integración de las TIC en las aulas ni, por tanto, su uso normalizado en el proceso de enseñanza-aprendizaje.

Por este motivo pretendemos presentar aquí algunos indicadores de Buenas Prácticas organizativas que conducirían a una mejora de la integración de las TIC en los centros educativos. Partimos de una revisión teórica del concepto de "Buenas Prácticas", así como del análisis de la política que ha llevado a cabo la Junta de Extremadura para la integración de estas Buenas Prácticas, anotando, por último, algunos de los resultados obtenidos en el marco de una investigación mucho más amplia en la que se realiza el estudio de varios casos de centros de Primaria y Secundaria que se considera que implementan Buenas Prácticas con TIC.

\section{2.-BUENAS PRÁCTICAS CON TIC}

El concepto de "Buenas Prácticas" es un término que tiene su origen en el ámbito empresarial y se usa como calificativo de cualquier actividad que ofrece buenos resultados en el contexto en el que se utiliza (De Pablos y González, 2007). Una definición que va en esta línea es la de Pere Marqués (2002) que entiende por "Buenas Prácticas docentes”:

Las intervenciones educativas que facilitan el desarrollo de actividades de aprendizaje en las que se logren con eficiencia los objetivos formativos previstos y también otros aprendizajes de alto valor educativo.

En este sentido, el término "Buenas Prácticas", si nos referimos al ámbito educativo, está en consonancia con el buen hacer didáctico (Palomo, Ruiz y Sánchez, 2006) y, normalmente, se reconocen externa e internamente como exitosas.

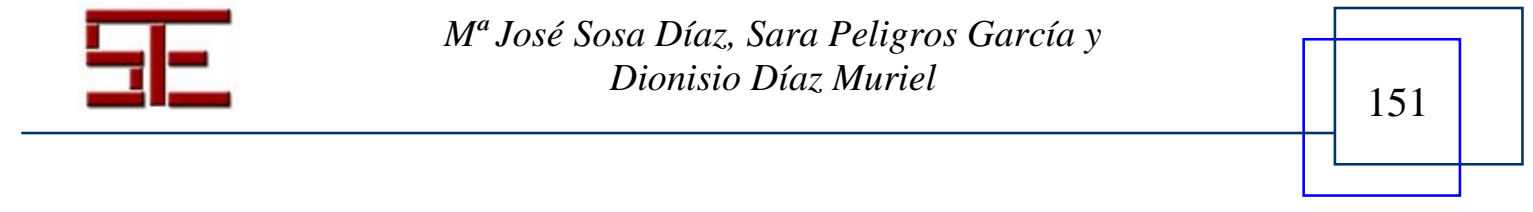




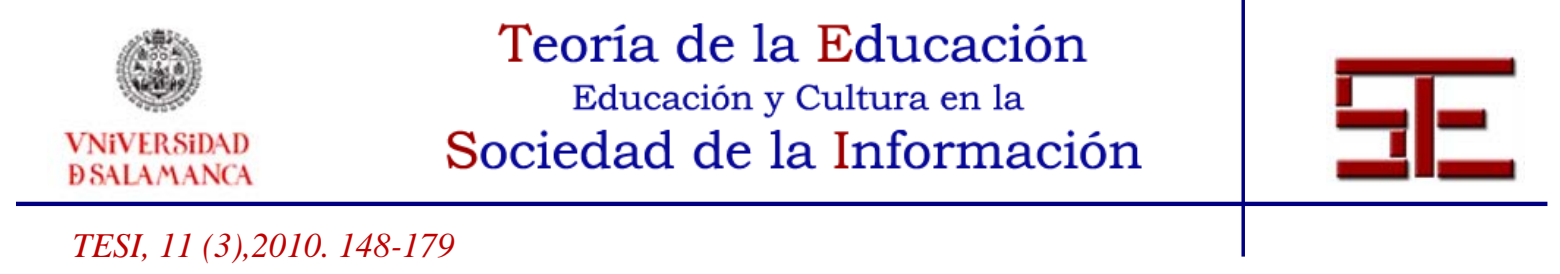

Por otro lado, Epper y Bates (2004) establecen cuatro características fundamentales de "Buena Práctica":

1. Mejora los resultados de un proceso.

2. Responde a una experiencia sistematizada, documentada y experimentada.

3. Aplica métodos innovadores.

4. Es extrapolable a otros contextos.

En definitiva, entenderemos por "Buenas Prácticas Educativas con Tecnologías de la Información y la Comunicación” toda aquella práctica educativa que con el uso de las TIC supone una mejora o potencialización del proceso de enseñanza-aprendizaje y por tanto de sus resultados, pudiendo servir, además, de referencia a otros contextos.

Por esta razón la simple instalación de los equipos informáticos o el uso de éstos con una metodología tradicional no originan "Buenas Prácticas”. Area (2007) afirma que "la tecnología informática por sí misma no genera aprendizaje de forma espontánea, sino que depende de los fines educativos, de los métodos didácticos y de las actividades que realiza el alumnado con los ordenadores en el aula”. Por tanto, no basta con instalar la infraestructura informática en los centros, sino que es necesario utilizarla y hacerlo de manera adecuada. Como bien dice Area (2007) "la calidad educativa no depende directamente de la tecnología empleada, sino del método de enseñanza bajo el cual se integra el uso de la tecnología, así como de las actividades que realiza el alumno con la misma”.

Ahora bien, Marqués (2002) sostiene que aunque todas las "Buenas Prácticas" suponen un buen hacer didáctico y pedagógico, no todas tienen la misma potencialidad educativa, por lo que creemos que es conveniente establecer una serie de indicadores que ayuden a identificar cuáles serían las mejores “Buenas Prácticas con TIC”.

Haciendo una revisión de diferentes indicadores de "Buenas Prácticas con TIC" que refieren distintos autores como: Chickering \& Erhman (1996), Márques (2002), Dulac (2004), Area (2007), Bernal y Rodríguez (2007), Casanova (2007), Valverde (2007) hemos elaborado un listado propio de indicadores que podrían ser relevantes para identificar Buenas Prácticas con TIC. Para ello hemos determinado tres ámbitos generales en los que se pueden reconocer Buenas Prácticas y que es conveniente reseñar:

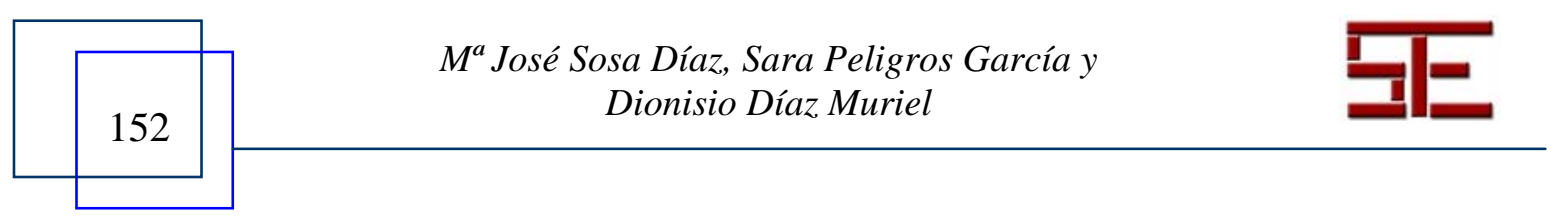




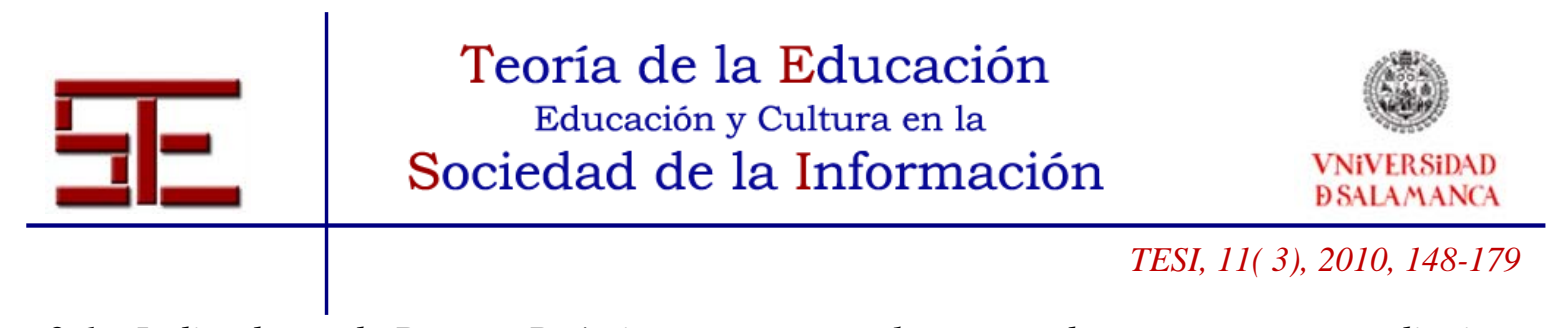

2.1.- Indicadores de Buenas Prácticas en cuanto al proceso de enseñanza-aprendizaje.

Casanova (2007) expone que "la innovación y las Buenas Prácticas con TIC giran en torno a unos objetivos: conseguir personas autónomas, críticas, con capacidad para desenvolverse en la mencionada Sociedad del Conocimiento". Como consecuencia de la formulación de este objetivo proponemos los siguientes indicadores de Buenas Prácticas:

- $\quad$ Aprendizaje autónomo: Las actividades con TIC que se realicen deben desarrollar la capacidad de uso inteligente de la información, impulsando al alumnado no sólo a adquirir información, sino a desarrollar habilidades cognitivas de análisis, síntesis, aplicación y evaluación, además de favorecer la ampliación de conocimiento y la conexión de ideas. Así pues, el papel del docente en el aula debe ser el de un organizador y supervisor de actividades de aprendizaje que los estudiantes realizan con las tecnologías, más que un transmisor de información elaborada (Área, 2007).

- $\quad$ Aprendizaje colaborativo: Las TIC son una poderosa herramienta de comunicación, sobre todo entre sujetos que no están en el mismo tiempo ni lugar, por lo que se deben implementar actividades que favorezcan un aprendizaje colaborativo.

- Creatividad: Las tareas fomentarán el pensamiento creativo y la construcción de conocimiento en el alumnado.

- $\quad$ Aprendizaje activo: Las TIC pueden ofrecer herramientas y recursos para "aprender haciendo" (obteniendo información, técnicas de simulación, etc.) que favorecerán un aprendizaje más significativo y profundo.

- Ampliación de conocimiento: Las tareas y actividades que se realizan con TIC permiten al alumnado ampliar conocimiento de forma autónoma y fomentar la conexión de ideas.

- Dificultades de aprendizaje: La metodología desarrollada por medio de las TIC respeta la diversidad de capacidades y modos de aprender (Chickering y Erhman, 1996) por lo que posibilita la superación de dificultades de aprendizaje. Los recursos educativos que se utilicen deben ser de elaboración propia o adaptados para que puedan responder de manera ajustada a las necesidades del alumnado y aprovechar adecuadamente todos los canales de transmisión del conocimiento (como son los visuales, auditivos, audiovisuales y textuales).

\section{2.- Indicadores de Buenas Prácticas en cuanto a la organización y gestión del centro}

A continuación se introducen algunos indicadores que proponemos para la identificación de “Buenas Prácticas” organizativas en la integración y uso de las TIC:

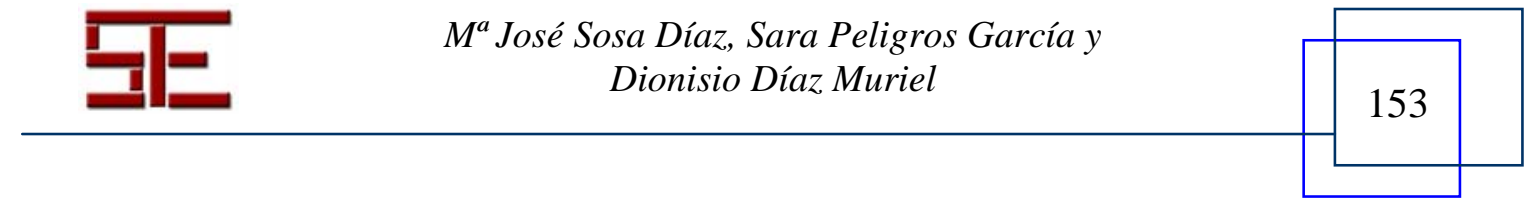




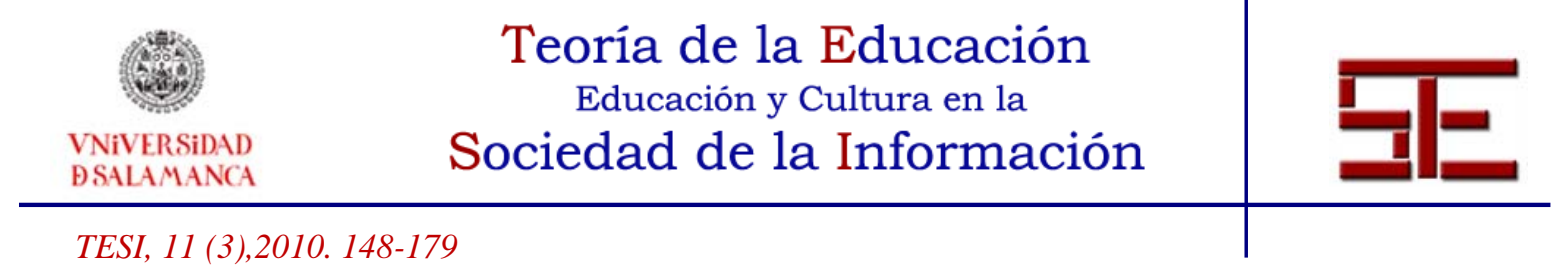

- $\quad$ Es muy importante la existencia de uno o dos coordinadores TIC en el centro educativo que impulsen y dinamicen el uso de estos recursos tecnológicos entre sus compañeros. Los coordinadores TIC deben tener bien definidas y reconocidas sus funciones. En muchos casos es recomendable formar un Equipo de Coordinación TIC para que no recaiga toda la responsabilidad de la coordinación en una única persona, ya que habitualmente no se dispone de suficiente tiempo como para ocuparse de todas las tareas encomendadas.

- $\quad$ Adecuada organización y coordinación de las aulas de informática, así como también de otros espacios y recursos TIC. Los equipos tecnológicos deberán estar accesibles y disponibles siempre que los usuarios requieran de su utilización.

- Implicación de los/as directores/as y del resto de miembros del equipo directivo y del claustro, y una formación en recursos informáticos apropiada.

- Utilización de herramientas TIC que favorezcan la comunicación entre todos los miembros de la comunidad educativa.

- Uso de herramientas TIC que permitan la gestión, administración y organización del centro y del aula de forma sencilla, rápida y eficaz.

- $\quad$ Oferta de formación adaptada a las necesidades TIC del profesorado, tanto en cuestiones técnicas como didácticas.

- $\quad$ Se fomentará la creación de grupos de trabajo y la colaboración entre los docentes, tanto en el trabajo diario como en la elaboración de materiales y recursos didácticos digitales.

\section{3.- Indicadores de Buenas Prácticas en cuanto a infraestructuras TIC}

- Utilización de software libre y aplicaciones de código abierto. La aportación más relevante de las aplicaciones de código abierto a las "Buenas Prácticas” en educación se encuentra en sus propios valores de colaboración, creatividad, solidaridad, innovación y calidad (Valverde, 2007).

- $\quad$ El hardware debe estar en las mejores condiciones y adaptado a los usuarios. Es importante la existencia de un Departamento de Tecnología Educativa en el centro que se encargue del mantenimiento óptimo de los equipos.

- $\quad$ Creación y actualización de una página web del centro que facilite la transmisión de información a la comunidad educativa y que almacene y difunda recursos educativos.

- $\quad$ Configuración de una intranet en el centro que funcione correctamente y que disponga de buena accesibilidad para todos los usuarios.

- $\quad$ En cada aula es precisa la existencia de al menos un equipo informático.

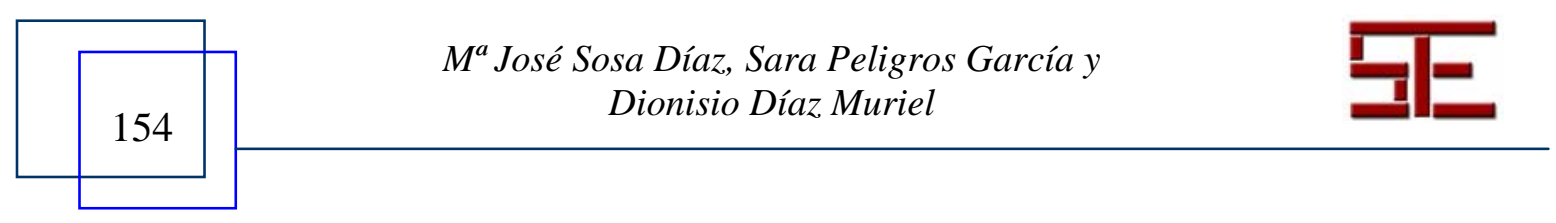




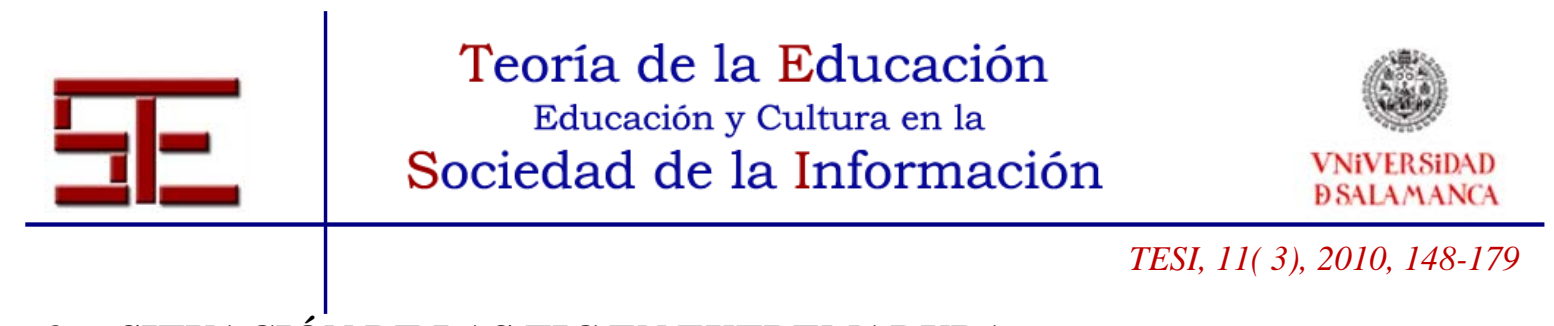

\section{3.- SITUACIÓN DE LAS TIC EN EXTREMADURA}

\section{1.- La red tecnológica educativa de Extremadura}

La Consejería de Educación, Ciencia y Tecnología, con el objeto de adaptar el Sistema Educativo Extremeño a la Sociedad de la Información y del Conocimiento, puso en marcha dentro del "Proyecto Global de la Sociedad de la Información" la "Red Tecnológica Educativa de Extremadura” (RTE). Con este proyecto se pretendía la dotación de toda la infraestructura necesaria: materiales informáticos, software propio que sirviera como herramienta para la docencia y la gestión administrativa, pasando por espacios para fomentar la investigación, la formación y la innovación.

En enero de 2000 la "Red Tecnológica Educativa de Extremadura" comenzó su andadura dividida en dos fases. Por un lado, la fase de vertebración en la que se dotó de todos los equipos informáticos (hardware, software, periféricos, etc.) a los Centros de Profesores y Recursos (CPR). Y, por otro, la fase de desarrollo en la que se extendió la Red a todos los centros educativos de la Comunidad Extremeña, se impulsó la formación de los docentes y la creación de contenidos digitales.

De este modo, los ejes fundamentales en los que se apoya la RTE pueden estructurarse en cuatro:

\subsection{1.- Dotación de la infraestructura tecnológica a todos los centros}

Las principales medidas que se llevaron a cabo para la dotación de infraestructuras tecnológicas fueron:

- Ampliación de la red de centros educativos adaptados para la incorporación de las infraestructuras tecnológicas.

- $\quad$ Equipamiento informático de las aulas. En los Institutos de Secundaria se dotaron las aulas con un ordenador por cada dos estudiantes; en los Centros de Primaria se crearon de entre dos a cinco aulas con ordenadores y se instaló al menos una pizarra digital interactiva, todos ellos dotados con el sistema operativo Gnu/Linex y sus correspondientes programas. Recientemente, ha sido aprobada una medida que se irá implantando progresivamente con la que se proveerá a todos los docentes y a cada estudiante de Secundaria de un ordenador portátil. El alumnado de Secundaria recibirá este portátil al entrar en $1^{\circ}$ de ESO.

- Establecimiento de la Intranet Regional que permite tener interconectadas todas las dependencias del gobierno regional.

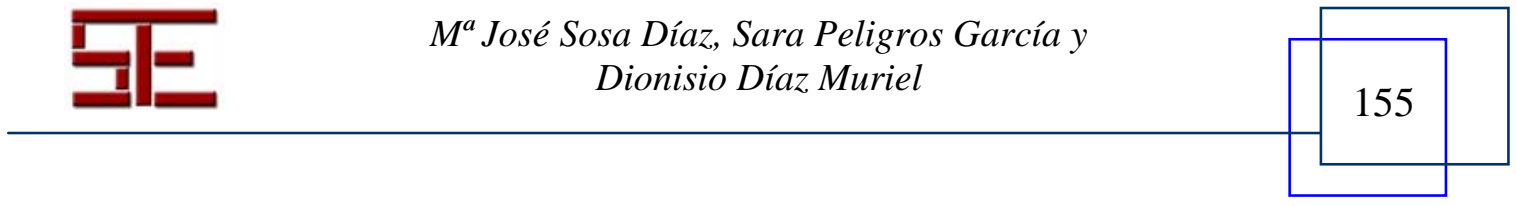




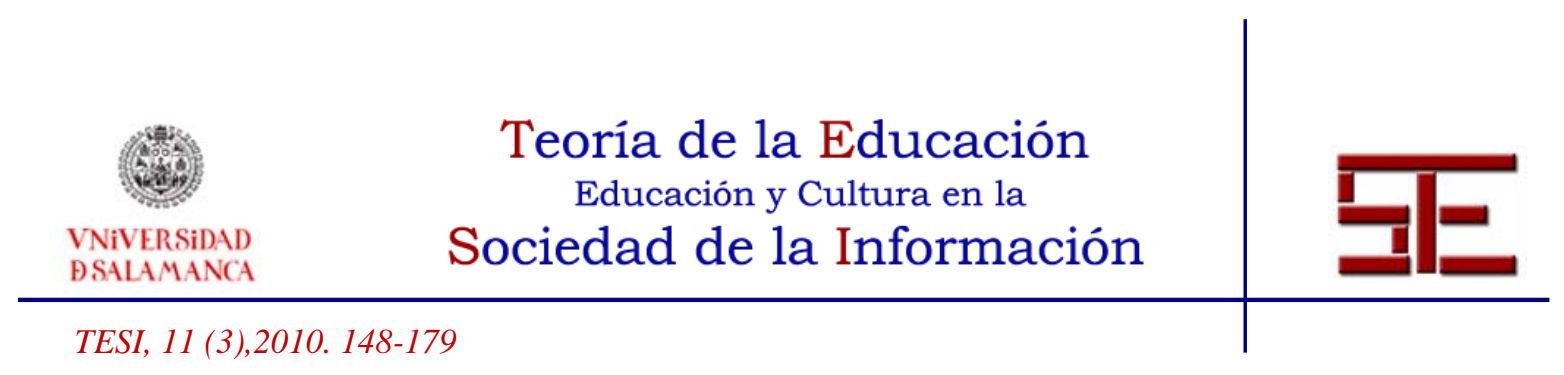

- $\quad$ Asignación de un Coordinador TIC para asesorar al profesorado en el uso de las tecnologías digitales y promover en el centro la dinamización de todas las iniciativas concernientes a la utilización de las TIC.

- Se proporcionó un Administrador Informático a todos los Institutos de Educación Secundaria y un Técnico Informático en cada Centro de Profesores y Recursos que atiende a los centros de Educación Infantil y Primaria de su demarcación. El Técnico en Informática se encarga del mantenimiento de los equipos y de la red, de la programación y ayuda en la elaboración de materiales didácticos.

- Se creó el Centro de Atención y Asistencia TIC que se encarga de gestionar aquellas incidencias del hardware que necesitan reparación técnica, sustitución de componentes, etc.

- $\quad$ Se dotó de un espacio web a todos los centros educativos y de correo electrónico a todos los docentes.

- $\quad$ Creación de un portal educativo de referencia para toda la comunidad educativa extremeña. Educar.ex contiene todos los servicios, información y contenidos digitales. En relación a algunas de las principales herramientas que contiene podríamos señalar: Populus.Forum, Populus.Vox, Atenex, Squeakpolis, @vanza, Web de Centros educativos, blog “En marcha con las TIC”, etc.

3.1.2.- Creación de softwares libres y propios que fueran útiles para la docencia y la gestión

La Consejería de Educación, Ciencia y Tecnología apostó desde un primer momento por el software libre e instaló LinEx en todos los centros no universitarios de Extremadura, ya que éste permitía:

- Tener un control sobre el parque informático que suponía llevar a cabo la RTE.

- Tener un sistema estable y potente para trabajar en red.

- Un software que permitiera realizar actualizaciones sin tener que depender de terceros y a un coste mínimo.

A fin de que LinEx tenga buena acogida y se generalice su utilización, la Administración ha puesto a disposición de todas las personas que deseen instalar, actualizar o consultar alguna duda referente a LinEx la página http://www.linex.org, donde además se puede continuar con la actualización del software para que cada vez sea más fácil, cómodo e intuitivo.

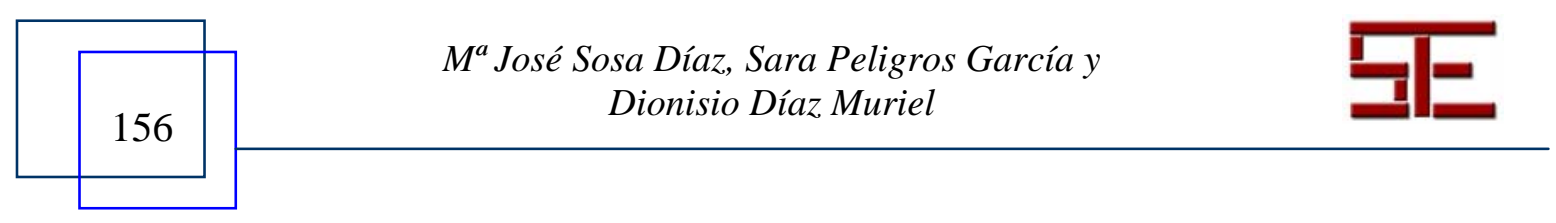




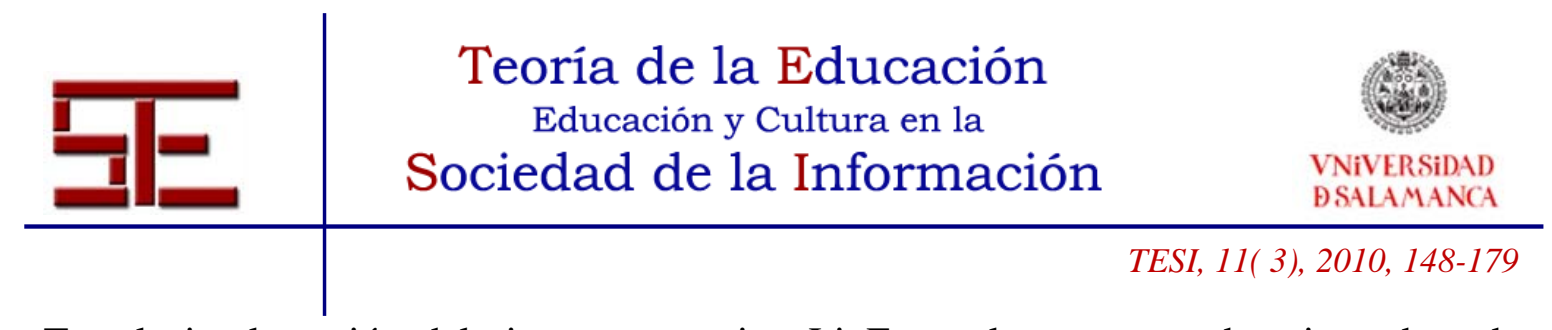

Tras la implantación del sistema operativo LinEx en los centros educativos de toda Extremadura el siguiente objetivo era la adaptación a todos sus posibles usuarios. En base a este motivo fue creado Linex Colegios, que a través de sus tres diferentes escritorios se ajusta a las necesidades educativas de cada etapa de Educación Infantil y Primaria. Existe un primer escritorio para el alumnado de Infantil, otro para los dos primeros ciclos de Primaria y un tercero para los cursos del último ciclo de esta etapa. Cada uno de ellos posee aplicaciones específicas y adecuadas a la edad de los educandos.

También el alumnado de Secundaria dispone de un software específico que les permite tener un acceso personalizado, con escritorio y carpetas propias y compartidas. Además, en los centros de Secundaria los docentes tienen a su disposición herramientas de control de aula como ControlAula o AulaLinex.

Por otro lado, es interesante destacar la creación de la plataforma Rayuela, una herramienta muy completa para la gestión y comunicación en los centros, cuyas características elementales recogeremos más adelante.

\subsection{3.- La formación del profesorado}

La administración educativa de Extremadura, con vistas a alcanzar la figura de un "profesor competente en TIC”, oferta a los docentes extremeños numerosas actividades formativas con el objetivo de que éstos adquieran habilidades técnicas y didácticas en TIC, de cara a rentabilizar las nuevas Aulas Tecnológicas:

- Cursos en el propio centro educativo.

- Cursos en los Centros de Profesores y Recursos.

- Grupos de Trabajo y Seminarios constituidos por los propios docentes.

- Ayudas individuales para asistir a actividades de formación.

- Licencias por estudios.

- Desarrollos de Jornadas Aula tecnológica siglo XXI.

- Cursos a distancia: @vanza, plataforma de formación on-line.

- Diversas publicaciones: libros, manuales, revistas u otro tipo de publicaciones mensuales donde se hace referencia al manejo de LinEx, sus programas y sus posibles usos didácticos.

En este punto es importante señalar la creación de una nueva figura: el profesor coordinador TIC, cuya función principal es impulsar y dinamizar el uso de las TIC entre sus compañeros. Cabría destacar que esta figura, que más adelante trataremos con detalle, no tiene por qué poseer conocimientos técnicos informáticos, ya que los

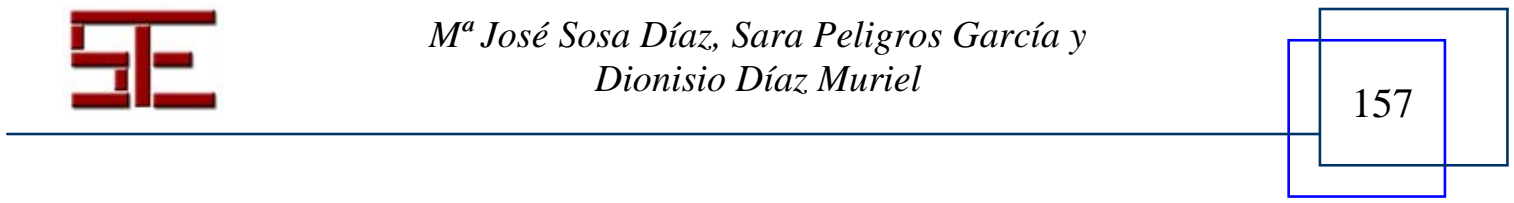




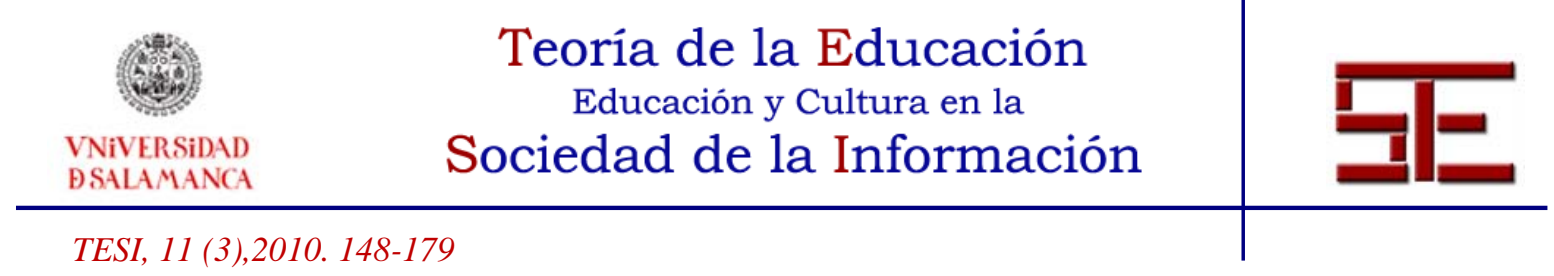

encargados del mantenimiento de los equipos y la instalación del software son los Administradores Informáticos.

\subsection{4.- Generación de contenidos digitales para la docencia.}

Para la generación de contenidos digitales se han tomado diversas medidas:

- Creación del Grupo Software Educativo (GSEEX), compuesto por profesores y profesoras de distintos niveles y áreas para la creación, selección, desarrollo de contenidos educativos digitales útiles y eficaces.

- Se creó un DVD con materiales didácticos digitales.

- En sus últimas versiones LinEx incorpora el apartado "LinEx Edu", con multitud de aplicaciones para todas las áreas y niveles educativos.

- Los contenidos creados por los docentes a iniciativa propia y que fueron compatibles con Gnu-LinEx se encuentran publicados en el portal www.educarex.es.

- Se realizan jornadas, cursos y grupos de trabajo coordinados por los Centros de Profesores y Recursos con el fin último de crear contenidos.

- En los premios a la innovación educativa "Joaquín Sama" se ha creado la modalidad de "Buenas Prácticas aplicadas a la educación” para contenidos curriculares interactivos.

- La Consejería concede ayudas para la creación de materiales curriculares.

- Anualmente se convocan los proyectos ATENEA para Primaria y ÁGORA para Secundaria. Estas convocatorias pretenden fomentar el uso de las TIC y la colaboración de todo el claustro del centro seleccionado, realizando actividades formativas específicas y proporcionando los recursos materiales y económicos para la creación de materiales.

- ATENEX es la plataforma de Creación y Gestión de Contenidos en el Aula. Pone a disposición del profesorado una plataforma colaborativa que permite crear, adaptar o modificar contenidos digitales curriculares de un modo sencillo y guiado. Además los docentes pueden contribuir con sus creaciones a la plataforma. Es importante indicar que ya cuenta con un bando de recursos educativos de más de 15.000 materiales catalogados.

\section{2.- Figura del coordinador TIC: su introducción como medida de calidad}

Entre las directrices prioritarias establecidas por la Consejería de Educación de la Junta de Extremadura en materia de política educativa se encuentran el desarrollo y uso de las "Buenas Prácticas de la Información y la Comunicación”, teniéndose en cuenta la actual realidad educativa extremeña donde la presencia generalizada de las TIC evidencia una inmersión de los centros docentes en la Sociedad de la Información.

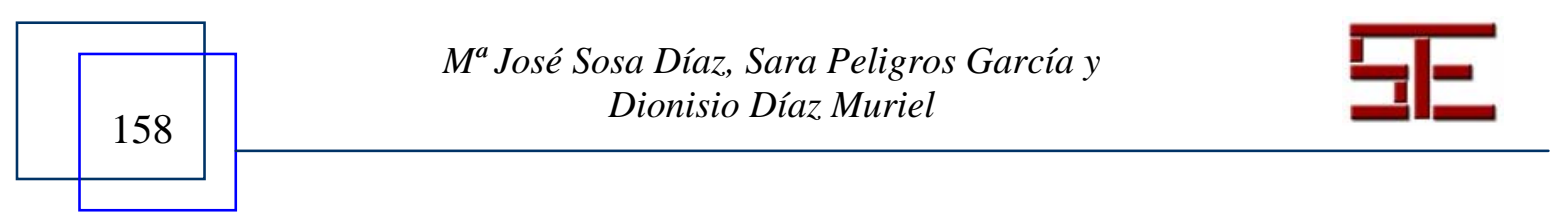




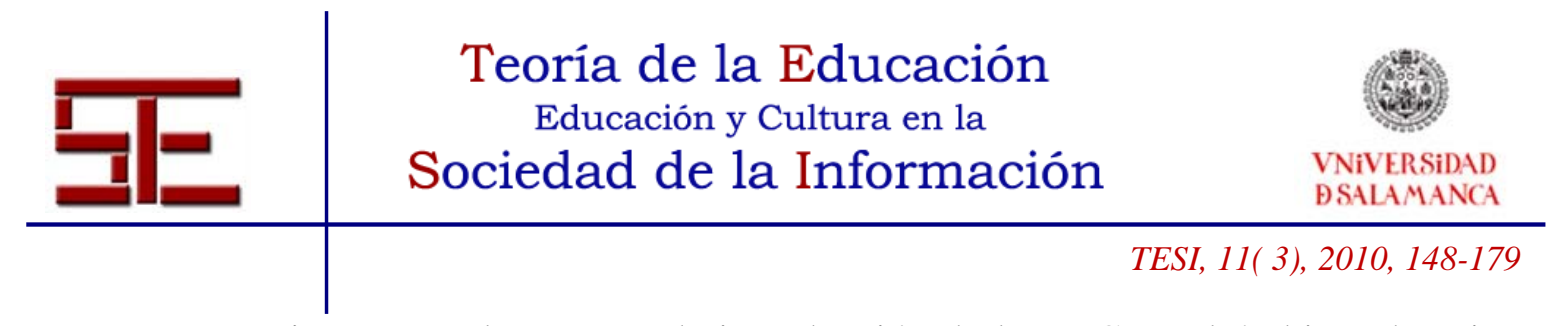

En aras a continuar con el proyecto de introducción de las TIC en el ámbito educativo de la región, la Secretaría General de Educación publicó las Instrucciones de 7 de julio de 2004, por las que se rigen los Centros de Secundaria y entre cuyos preceptos se detallan ciertas consideraciones en lo referente a la integración de los medios tecnológicos en la enseñanza secundaria, la organización y el funcionamiento de los IES:

En la instrucción I. El proyecto educativo de centro, relativa a la elaboración del PEC, se especificarán entre otros el plan de integración de las Tecnologías de la Información y la Comunicación (TIC) en los diversos aspectos de la vida del centro, que se dirigirá al menos a los siguientes puntos:

- Las TIC como recurso didáctico de acuerdo con lo que establezca el Proyecto Curricular.

- Las TIC como medio de comunicación entre los distintos agentes implicados en el proceso educativo: docentes, alumnado, familias, administración, etc.

- Las TIC como recurso para la organización, gestión y administración del centro.

Para la elaboración, revisión, seguimiento y evaluación de los Proyectos Curriculares de Etapa se prestará especial atención a la utilización de las Tecnologías de la Información y la Comunicación como recurso didáctico al servicio de la enseñanza de las distintas áreas y, por tanto, relacionadas con la programación didáctica de las distintas materias (I.2 12 b). Asimismo, en las Programaciones Didácticas de los Departamentos deberá aparecer un apartado concreto sobre la Integración de las Tecnologías de la Información y Comunicación como recurso didáctico, haciendo referencia a los contenidos y/o actividades en los que se utilizarán, así como a la previsión de actuaciones que se van a realizar para la ampliación y mejora de su utilización (I.2.2 17). Del mismo modo, la Programación General Anual contemplará una descripción del plan de integración de las TIC para el curso escolar (I.3).

Según esta normativa, en cada IES o IESO se creará la figura del Profesor/a Coordinador/a de Tecnologías Educativas, nombrado/a por el Director o Directora cada curso académico de entre el profesorado que preste sus servicios en el centro. Con acreditada experiencia en la gestión de las TIC con fines educativos, elaborará, de acuerdo con el Equipo Directivo y contando con el apoyo técnico del Programador Informático, el programa anual de trabajo que se incorporará a la Programación General Anual y que tendrá al menos los siguientes apartados (I.3.2. Programa de Integración de las TIC):

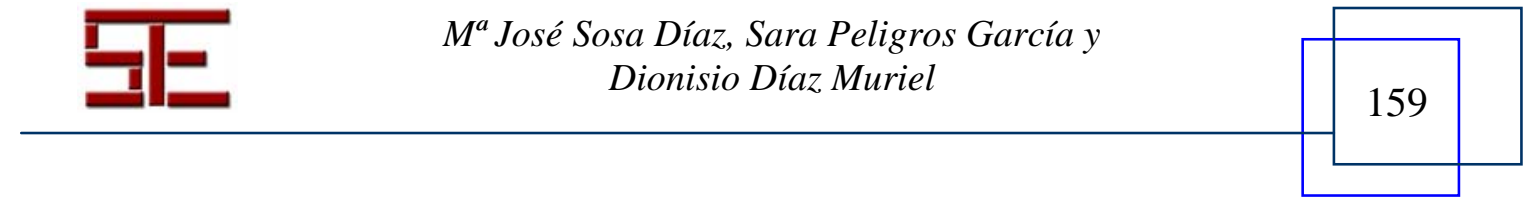




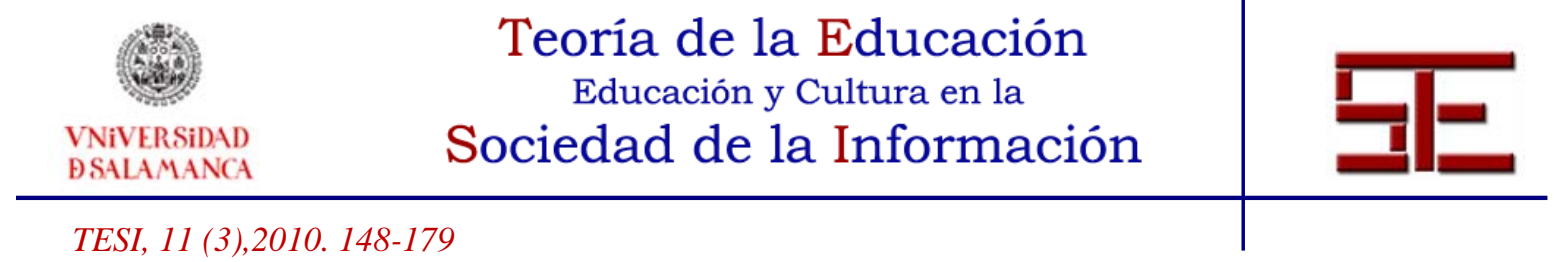

a) Actuaciones previstas para la dinamización del Centro, de los recursos y materiales y para la integración curricular de las tecnologías de la información y la comunicación en las distintas áreas y materias.

b) Actuaciones previstas para la potenciación de los mecanismos de relación en la comunidad educativa utilizando las Buenas Prácticas.

c) Actuaciones para difundir entre el profesorado y el alumnado la información y los recursos informáticos, audiovisuales y multimedia.

d) Diseño del seguimiento y evaluación del programa.

Las funciones del profesor/a coordinador/a de Tecnologías Educativas aparecen recogidas en la I.3.7. del documento legal, enumerándose las citadas a continuación:

a) Organizar los recursos educativos relacionados con las TIC (especialmente software educativo) a los que tenga acceso el Centro, contando con el apoyo técnico del Programador Informático.

b) Informar al profesorado sobre las nuevas herramientas, los productos $\mathrm{y}$ sistemas disponibles para la educación y difundir su utilización en el aula.

c) Apoyar al profesorado en la integración de las TIC en el currículum.

d) Actuar como dinamizador e impulsor en el Centro de cuantas iniciativas y proyectos surjan entre el profesorado y el alumnado, relacionados con las Buenas Prácticas y la educación.

e) Cualquier otra que le encomiende la Dirección del Centro en relación con su ámbito de competencias.

Respecto a la distribución de horas dedicadas a las actividades propias de la coordinación de las Tecnologías Educativas, para el profesor o profesora encargado/a de tales tareas, a efectos del cómputo de los períodos lectivos semanales se le considerarán lectivos tres períodos.

Otro de los puestos creados con la finalidad de apoyar una adecuada utilización, mantenimiento y gestión de los recursos informático-tecnológicos en los Institutos de Educación Secundaria es el del Programador Informático, cuyas funciones y ámbitos de actuación también quedan recogidos. Entre sus cometidos se enuncian:

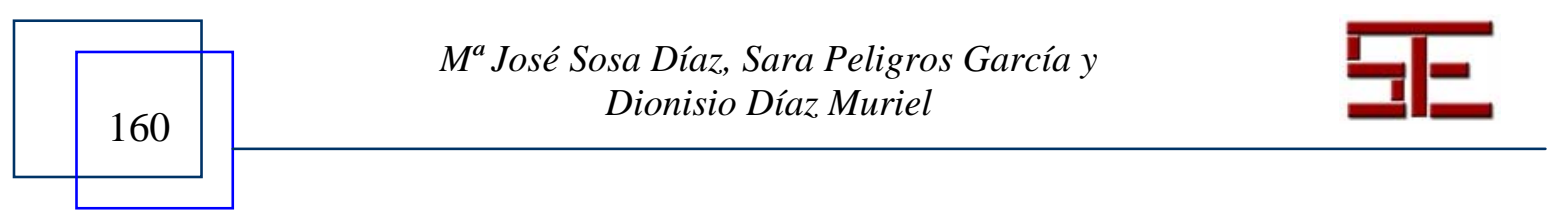




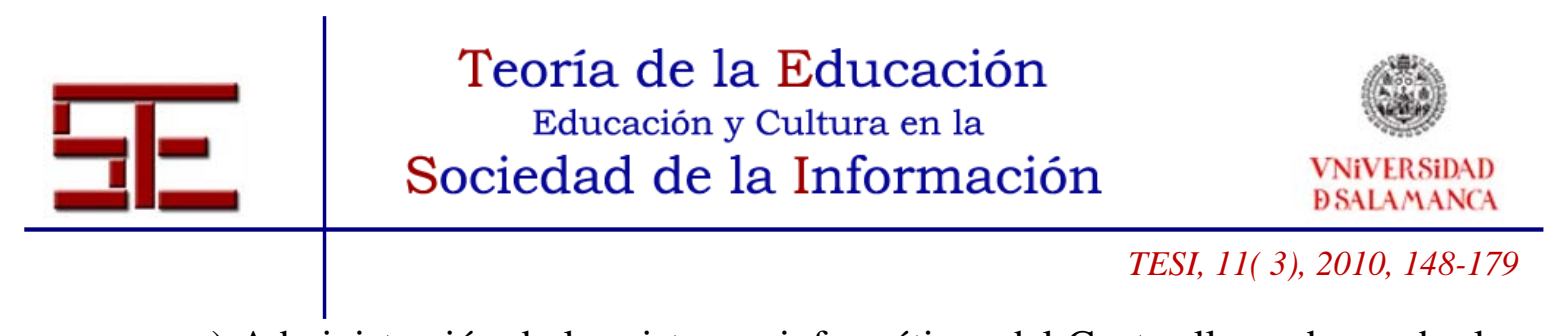

a) Administración de los sistemas informáticos del Centro llevando a cabo las tareas de gestión de usuarios, actualización del sistema operativo Linex, mantenimiento de la red, realización de copias de seguridad, diagnóstico de problemas y reparación de los mismos de acuerdo con las directrices de la Secretaría General de Educación.

b) Custodia de las contraseñas de root que sólo será compartida con el Director/a del Centro para garantizar la seguridad de los sistemas. Si otras personas del Centro necesitasen privilegios de root, éstos se le darían a través de otros medios.

c) Comunicación de todos los cambios significativos en la configuración de los servidores, conjunto de los clientes, políticas de seguridad, etc., a la Secretaría General de Educación para que se estudie su conveniencia y, en su caso, la extensión de los mismos a todos los Centros.

d) Mantenimiento de los soportes físicos realizando las tareas de reparación y mantenimiento así como la elaboración de la documentación necesaria para el correcto uso de los equipos.

e) Mantenimiento de los soportes lógicos efectuando la instalación y actualización del software necesario para las tareas docentes y administrativas.

f) Mantenimiento de la seguridad ante posibles ataques a los sistemas informáticos.

g) Apoyo y asesoramiento técnico al profesorado dedicado a la elaboración de materiales didácticos interactivos para el aula.

h) Apoyo técnico a las tareas administrativas del Centro asesorando en el uso y explotación de las aplicaciones de gestión.

i) Apoyo técnico en la elaboración y mantenimiento del portal del Centro así como el favorecimiento de las posibles comunicaciones con otros Centros y con la Administración Educativa.

j) Aquellas otras tareas que le sean encomendadas por el Director/a del Centro relacionadas con los sistemas informáticos.

En Educación Infantil y Primaria, hasta el curso 2006-2007 no se regula la implantación de la figura del/a Coordinador/a TIC, mediante las Instrucciones de 27 de junio de 2006

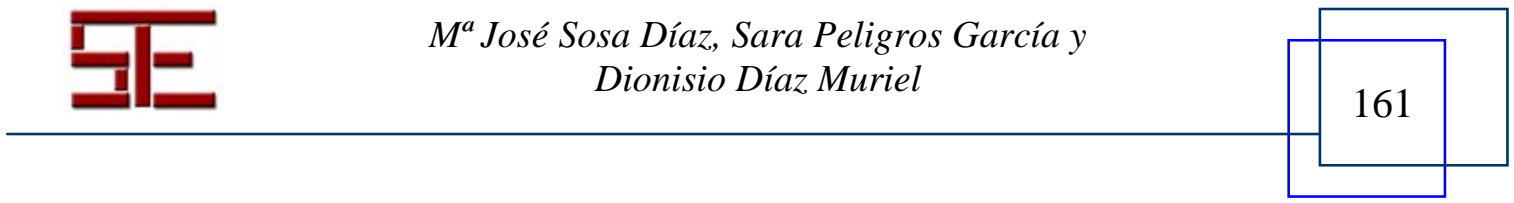




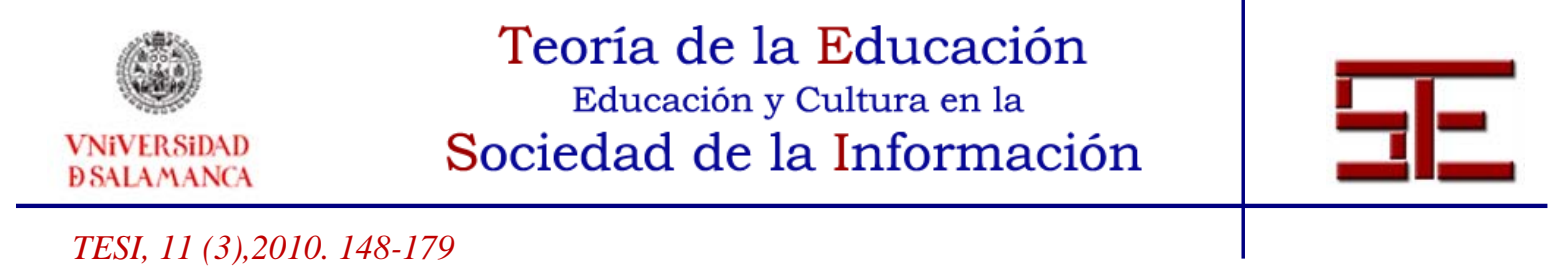

de la Dirección General de Política Educativa, sumándose a la normativa anteriormente creada para los IES.

Igual a lo dispuesto para los Centros de Secundaria, el Proyecto Educativo de Centro contendrá aquellas cuestiones concernientes a la integración de las TIC en los diversos aspectos de la vida del Centro, todo ello dirigido al menos a los siguientes ámbitos (I.1.6):

- Como recurso didáctico de acuerdo con lo que establezca el Proyecto Curricular.

- Como medio de comunicación entre los distintos agentes implicados en el proceso educativo: docentes, familias, administración, etc.

- Como recurso para la organización, gestión y administración del Centro.

Las estrategias metodológicas y la integración de las TIC como recurso didáctico, haciendo especial referencia a los contenidos y/o actividades en los que se utilizarán, es otra de las secciones de obligada redacción en las Programaciones de Aula. Además, dentro de la Programación General Anual han de mencionarse las previsiones de actividades referidas al Proyecto de Integración de las TIC en el aula para el curso académico correspondiente.

La instrucción I.6, en el apartado 47 i) aclara que la Memoria Final deberá contener, al menos, los elementos que sirvan de indicadores del funcionamiento del centro sobre el aprovechamiento de los medios y recursos didácticos con especial análisis del uso de las TIC.

En este caso, el/la Coordinador/a del Proyecto de Integración de las Tecnologías de la Información y la Comunicación en el aula, dentro de los Centros de Primaria e Infantil (nombrado/a por el Director/a del centro, de entre el profesorado del claustro con acreditada experiencia en la gestión de las TIC con fines educativos), actuará siempre bajo la dependencia del Jefe de Estudios, desempeñando las funciones que siguen:

a) Elevar propuestas al Equipo Directivo para la elaboración del Proyecto de Integración de las Tecnologías de la Información y la Comunicación en los diversos aspectos de la vida en el Centro.

b) Coordinar las actividades que se realicen en el Centro en relación con el uso de estos medios.

c) Organizar y gestionar los medios y recursos de que dispone el Centro y mantenerlos operativos y actualizados.

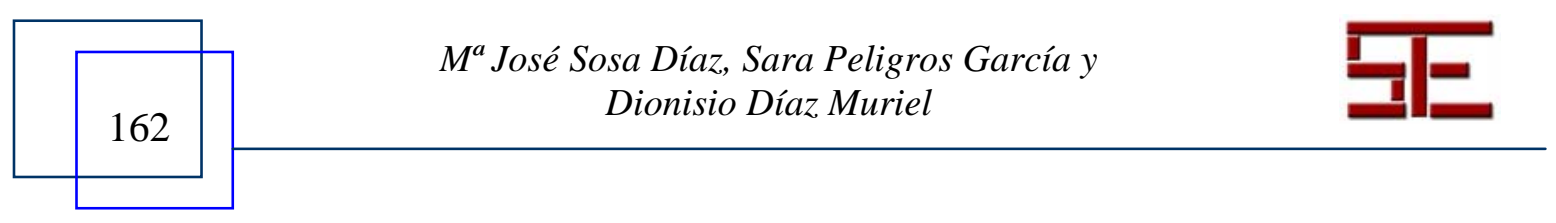




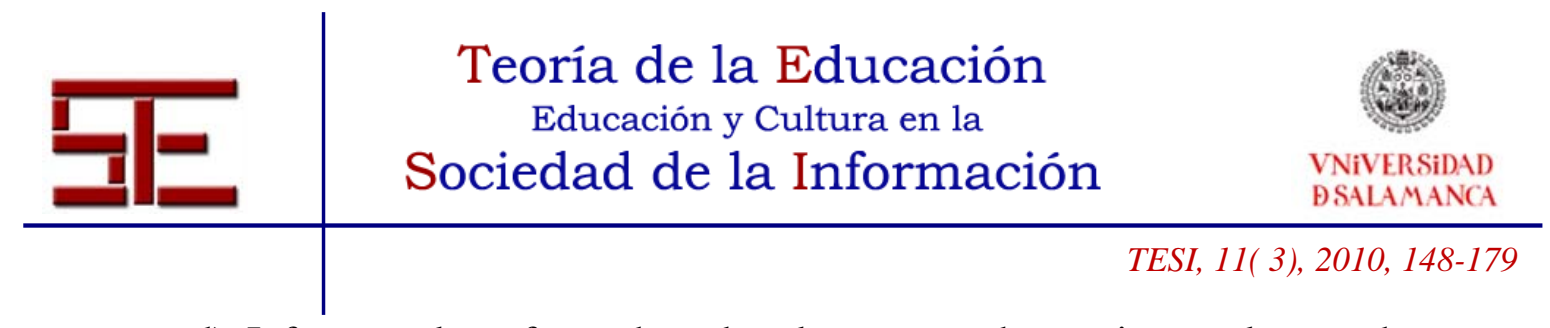

d) Informar al profesorado sobre las nuevas herramientas, los productos y sistemas disponibles para la educación y difundir su utilización en el aula.

e) Apoyar al profesorado en la integración de las Buenas Prácticas informáticas y audiovisuales en el currículum.

f) Actuar como dinamizador e impulsor en el Centro de cuantas iniciativas y proyectos surjan entre el profesorado y alumnado, relacionados con las Buenas Prácticas y la educación.

g) Cualquier otra que le encomiende el Jefe de Estudios relativa a la utilización de los medios audiovisuales o de las TIC como recurso didáctico.

Aludiendo a lo escrito en el Anexo II de las Instrucciones, dentro del apartado orientaciones para el desarrollo de los programas y proyectos de los centros se incluye un punto acerca de la elaboración de un Proyecto de Integración de las TIC en la Educación, que se incorporará a la Programación General Anual y tendrá en cuenta, al menos, los siguientes apartados:

a) Gestión de las aulas con dotación informática y audiovisual: horarios y criterios de utilización.

b) Actuaciones previstas para la dinamización del centro, de los recursos y materiales y para la integración curricular de las Buenas Prácticas de la información y la comunicación en las distintas áreas.

c) Actuaciones previstas para la potenciación de los mecanismos de relación en la comunidad educativa utilizando las Buenas Prácticas.

d) Actuaciones para difundir entre el profesorado la información y los recursos informáticos, audiovisuales y multimedia.

e) Diseño de seguimiento y evaluación del proyecto.

El diseño de este proyecto de trabajo anual correrá a cargo del profesor/a coordinador/a de Buenas Prácticas de la Información y la Comunicación, de acuerdo con el Equipo Directivo.

La importancia del/a profesor/a que encabeza la coordinación de las TIC en los centros radica en que dicho agente no sólo es técnico o en cierta medida "experto" en lo concerniente al uso y mantenimiento del aparataje tecnológico, sino que también debe

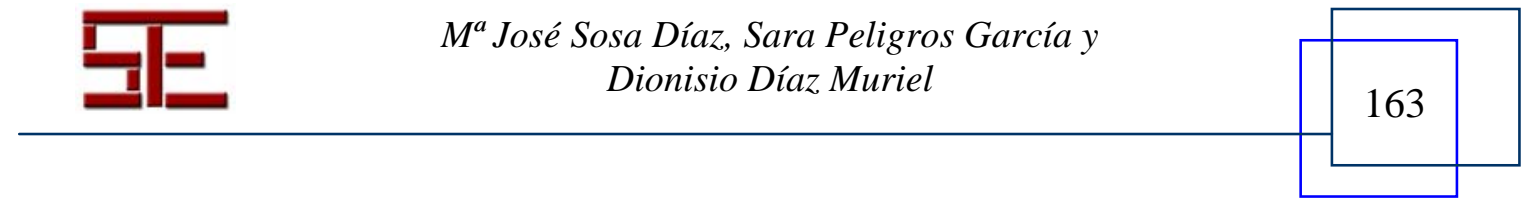




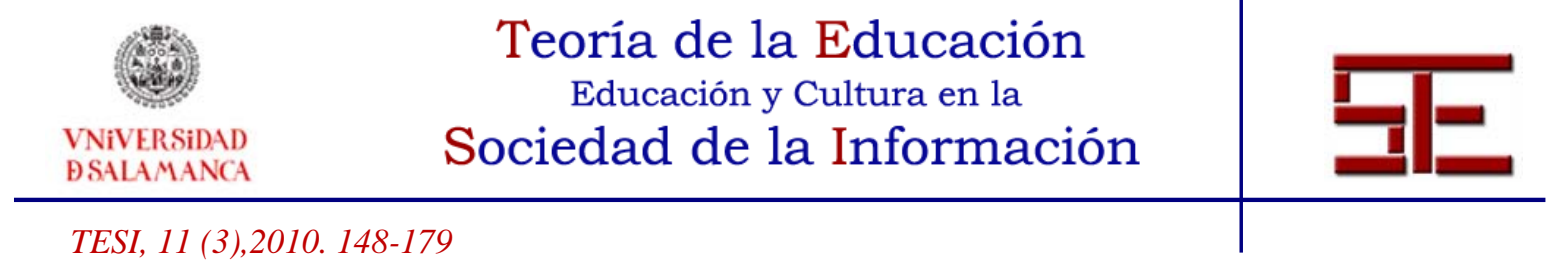

ser animador, dinamizador educativo, estimulador de la actividad del profesorado, figura que canaliza la reflexión general, debate y consensúa, motiva el cambio de mentalidad y metodología, presenta iniciativas, realiza y potencia la creación de materiales curriculares, ayuda a solventar problemas, forma, acude a las clases, instruye a sus colegas para que aprendan el funcionamiento técnico de las herramientas informáticas..., y todo ello con la perspectiva global de favorecer el uso de estrategias, bien docentes u organizativas, que tengan presentes las Tecnologías de la Información y la Comunicación en el centro.

La instauración de la figura del/a coordinador/a TIC lleva parejas mejoras en la asistencia al profesorado sobre la utilización de las Buenas Prácticas, combinando un asesoramiento técnico y una orientación pedagógica con objeto de rentabilizar adecuadamente las aulas informatizadas.

\section{3.- Aulas tecnológicas}

Con la implantación de todas las medidas estratégicas llevadas a cabo por la Administración Educativa de la Comunidad Autónoma de Extremadura para la integración de las TIC, la instalación de los equipos informáticos en todos los centros educativos públicos de la región, independientemente de su situación geográfica o entorno socioeconómico, responde a una ratio de un ordenador por cada dos estudiantes en Educación Secundaria y un ordenador por cada seis en Infantil y Primaria. Aparece, con todo, un concepto nuevo como es el de "Aula tecnológica".

Así pues, todas las aulas de los centros de Educación Secundaria Obligatoria y Bachillerato, a excepción de las aulas específicas, cuentan con un ordenador dispuesto en una mesa de dos usuarios, más el equipo del/a profesor/a. Todos estos ordenadores van dotados del sistema operativo y los programas de Gnu-LinEx, además de conectividad y acceso a Internet. Normalmente, a causa de las características físicas de las aulas, de los inmuebles y los equipos informáticos, la disposición del alumnado obligatoriamente sigue una organización "tradicional” del aula. Las mesas, cada una con un ordenador, se disponen una detrás de otra, mirando hacia la pizarra y la mesa del docente, sin posibilidad de cambios debido al cableado y el peso de las mesas.

\subsection{1.- Disposición del Aula tecnológica en Secundaria}

Recientemente, tal como comentábamos unas líneas más arriba, ha sido aprobada otra nueva medida que se irá implantando paulatinamente, gracias a la que se proveerá a todos los docentes y a cada uno de los/as alumnos/as de enseñanza Secundaria de un PC portátil. Con ello, cada estudiante de Secundaria recibirá un portátil al iniciar $1^{\circ}$ de ESO.

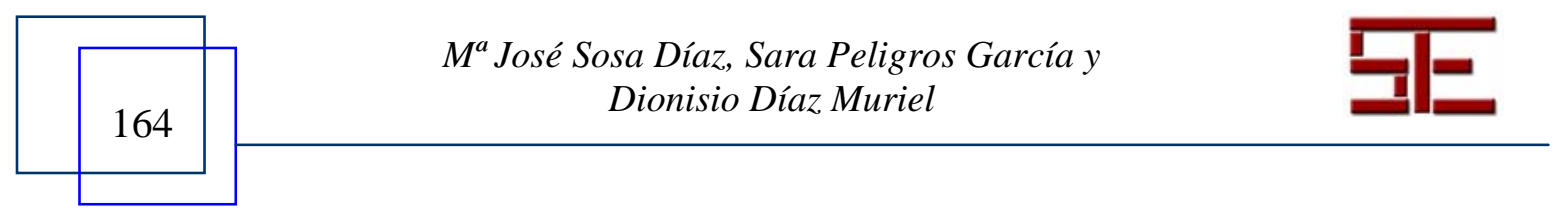




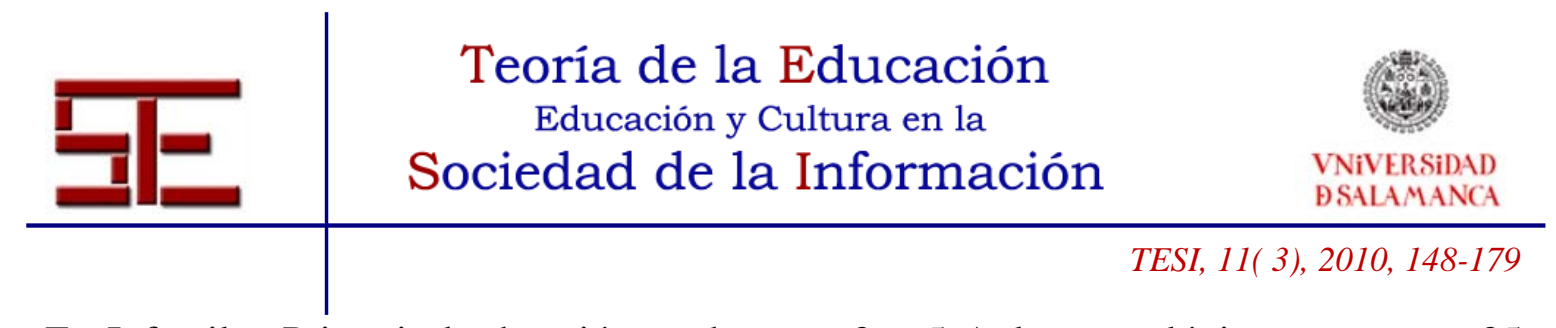

En Infantil y Primaria la dotación es de entre 2 y 5 Aulas tecnológicas, con unos 25 equipos informáticos en cada una (un ordenador cada cinco o seis estudiantes). Además, disponen de al menos una pizarra digital interactiva por centro, conjunto formado por un proyector, un ordenador y un tablero interactivo. En este caso, aunque las aulas aún no son flexibles, las soluciones de distribución y agrupamiento del alumnado son mucho más variopintas.

3.4.- Herramientas TIC utilizadas a nivel organizativo en los Centros (Rayuela, ControlAula y AulaLinEx)

La dotación de recursos tecnológicos en los centros educativos ha planteado diversos problemas organizativos, ya que no había un modelo parecido precedente en el cual fijarse. La práctica diaria ha llevado a buscar soluciones de gestión y organización tanto a nivel de aula como a nivel de centro. Por un lado, a nivel de aula se han desarrollado dos herramientas: Control Aula y AulaLinEx, y, por otro, a nivel de centro se ha creado Rayuela, una plataforma educativa para la gestión de los centros docentes.

a) AulaLinEx es una aplicación específicamente diseñada para mejorar el proceso de enseñanza-aprendizaje con apoyo informático en las Aulas tecnológicas de la Junta de Extremadura. Se trata de una herramienta creada por docentes para docentes, cuya finalidad principal es dar una respuesta real a algunas de las necesidades y problemas que se plantean a la hora de integrar los ordenadores en su trabajo diario. Con este programa el profesorado podrá enseñar, controlar y ayudar a sus estudiantes, proporcionándoles un lugar en primera fila y la oportunidad de obtener una atención personalizada e inmediata. Las características más destacables:

- $\quad$ Fácil manejo: AulaLinex posee una interfaz gráfica amigable constituida por una barra de herramientas, una barra de menús, un panel de opciones y un conjunto de botones gráficos que simulan los equipos del aula. Basta con un simple clic de ratón para ejecutar la función elegida en el ordenador u ordenadores deseados.

- $\quad$ Configurable: Permite simular totalmente la organización de cada grupoclase concreto: número de filas y equipos, nombre y situación del alumnado de cada grupo, programas que utiliza cada profesor/a en la asignatura que imparte...

- Flexible: Por otro lado, posibilita la creación de "aulas virtuales", es decir, compuestas por un/a profesor/a y un grupo de alumnos y alumnas que, físicamente, pueden estar en clases diferentes. Constituye un mecanismo para dar una respuesta homogénea a discentes con necesidades educativas similares (superdotados, ACNEE...) sin tener que recurrir a agrupamientos, a veces, contraproducentes.

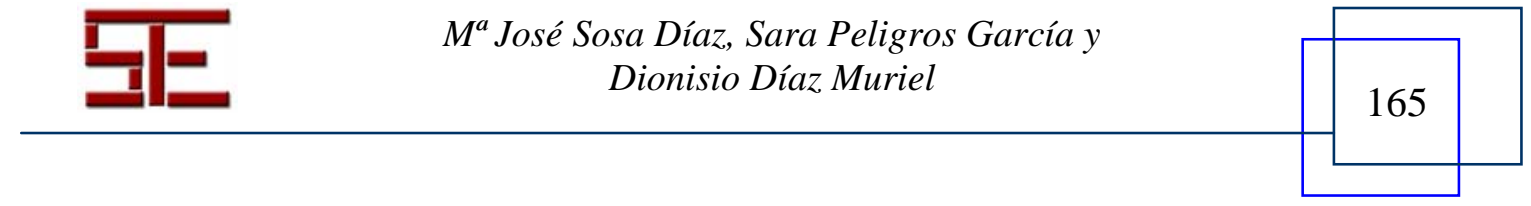




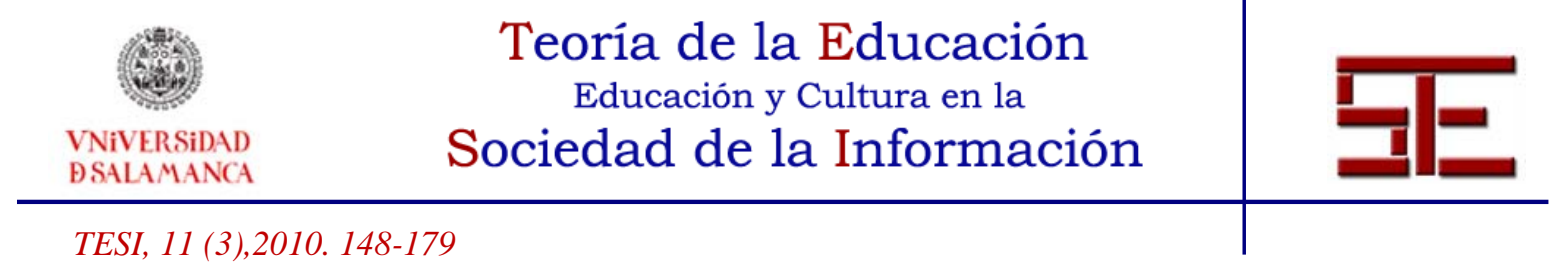

- $\quad$ Múltiples funciones entre las que destacan: La pizarra digital; Envío y recepción automática de archivos y carpetas; Ejecución remota de aplicaciones; Remisión de mensajes; Visionado remoto de vídeos; Presentación del alumno; Inicio y almacenamiento de las páginas web elegidas; Apagado y encendido remoto; Monitorización de las pantallas de los alumnos/as; Desactivación de la conexión a Internet; Control del teclado y ratón de un estudiante; Detección y/o apagado automático de los equipos; Pantalla de selección de programas.

- Instalación simple: El programa se distribuirá bajo licencia GPL en dos paquetes Debian, profelinex y alumnolinex, que se obtiene en la zona de descarga de LinEx.

b) ControlAula es una aplicación similar a la anterior que consiste en una herramienta para facilitar al profesor el control del aula en un Centro educativo. Está compuesta por un servidor y un cliente que se instalan en todos los puestos. El servidor atiende las peticiones del programa cliente que es el que maneja el profesor.

c) Rayuela es una plataforma educativa para la completa gestión y comunicación de los centros. Es un avanzado sistema de información que, vía Internet, permite a los Centros la gestión académica, la gestión administrativa y el seguimiento educativo a través de una única plataforma.

La información que contiene Rayuela es única y está disponible en tiempo real mediante el acceso a Internet. Toda Comunidad Educativa, y en especial el personal responsable de la gestión, administración y docencia del centro, puede acceder a la plataforma. Este acceso es personalizado mediante claves únicas por usuario, puesto que a través de distintos perfiles la plataforma reconoce y posibilita el acceso a unos determinados datos y a las funcionalidades de acuerdo a las responsabilidades que este usuario tenga dentro del centro. Se establecen así diferentes perfiles dentro de la plataforma, entre los que tenemos: dirección, profesorado, padres/madres, alumnado.

Rayuela oferta principalmente cuatro servicios bien diferenciados:

- El Sistema de Gestión de Centros realizará todos los procesos administrativos y académicos, como la gestión de admisión de alumnos/as, matriculación, gestión económica, etc.

- La Secretaría Virtual permite realizar los trámites administrativos mediante procedimientos telemáticos. A través de ella se podrán realizar solicitudes de admisión de alumnos/as, inscripciones, solicitudes de pruebas de acceso, entre otros servicios, sin desplazarse a los centros.

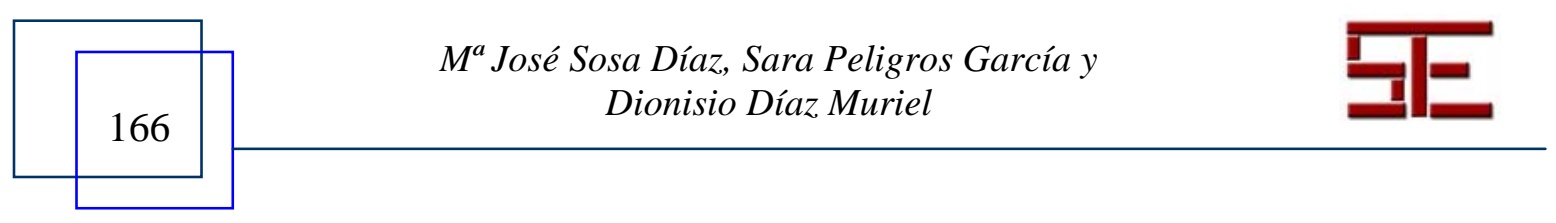




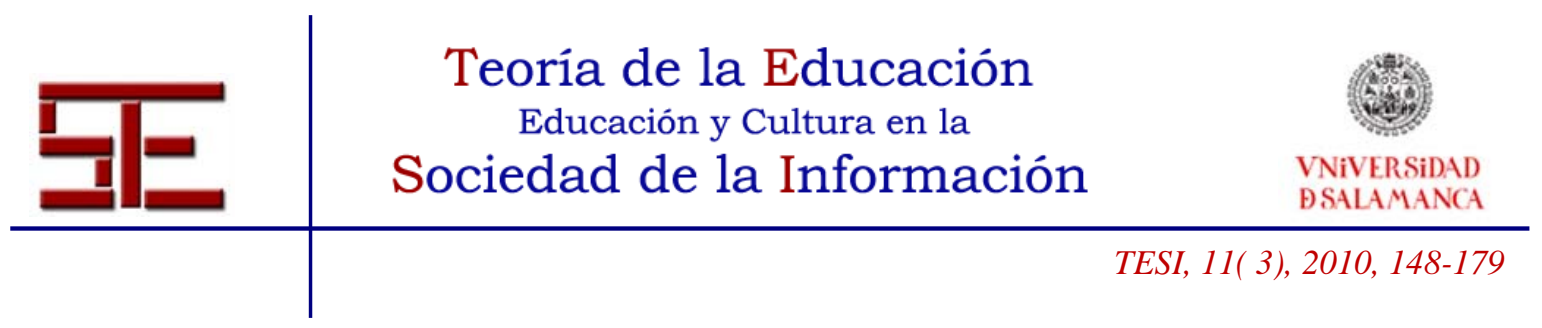

- $\quad$ Formación en Red y Apoyo a través del Centro de Atención al Usuario. Este servicio está formado por un equipo de expertos en el manejo de Rayuela que informarán y atenderán al usuario tanto a través de la web http.//rayuela.educarex.es, por correo electrónico o telefónicamente.

- El Sistema de Seguimiento Educativo. En Rayuela se encuentra el Expediente Académico Digital de cada alumno, que contiene información sobre todos sus años de escolaridad (calificaciones, faltas de asistencia, adaptaciones curriculares, observaciones, etc.) y que puede consultar el docente para ofrecer una atención personalizada e individualizada, o también comunicar a los padres y madres información diaria sobre las faltas, los exámenes, los trabajos, notas y todo lo relacionado con el aprendizaje de los escolares. De esta forma, cualquier padre o madre puede participar de la evolución académica de sus hijos e hijas. Permite, asimismo, una nueva vía de comunicación entre todos los miembros de la comunidad educativa, ya que tanto las familias, como los docentes y el propio alumnado podrán comunicarse a través de esta plataforma.

Otra de las utilidades que Rayuela ofrece a sus usuarios es el acceso a novedades, noticias y otros datos que el Centro considere necesarios y oportunos, mediante el envío de avisos o publicando a través de su tablón, y todo ello siempre de forma segura y personalizada. Por último, las Asociaciones de Padres y Madres de alumnos/as y el Consejo Escolar dispondrán de espacio para la gestión de todas sus actividades como la gestión de la filiación, tablón de anuncios de actividades, gestión de los asuntos generales, entre otras.

\section{4.- METODOLOGÍA DE LA INVESTIGACIÓN}

La investigación en la que se encuadran los estudios de caso lleva por título Análisis de las políticas educativas para la integración y uso de las TIC en el sistema educativo de Extremadura y sus efectos en la innovación educativa ${ }^{1}$. Este proyecto propone el análisis de las políticas educativas de la Comunidad de Extremadura en relación a la introducción de las TIC, además de la identificación del desarrollo de Buenas Prácticas con TIC, a través del estudio de nueve centros educativos no universitarios, con el fin último de elaborar una Guía de Buenas Prácticas TIC.

La selección de los nueve centros educativos, entre los que se encuentran cuatro centros de Educación Infantil y Primaria y cinco Institutos de Educación Secundaria Obligatoria, se efectuó mediante el análisis cualitativo de la entrevistas a los asesores de los Centros de Profesores y Recursos (CPR) pertenecientes a las distintas comarcas de

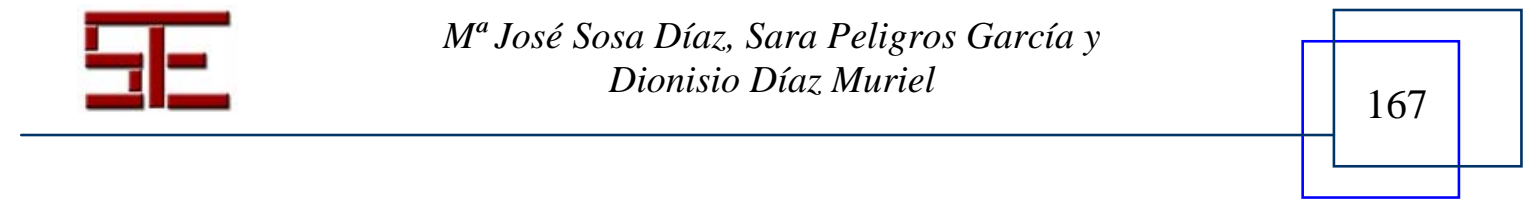




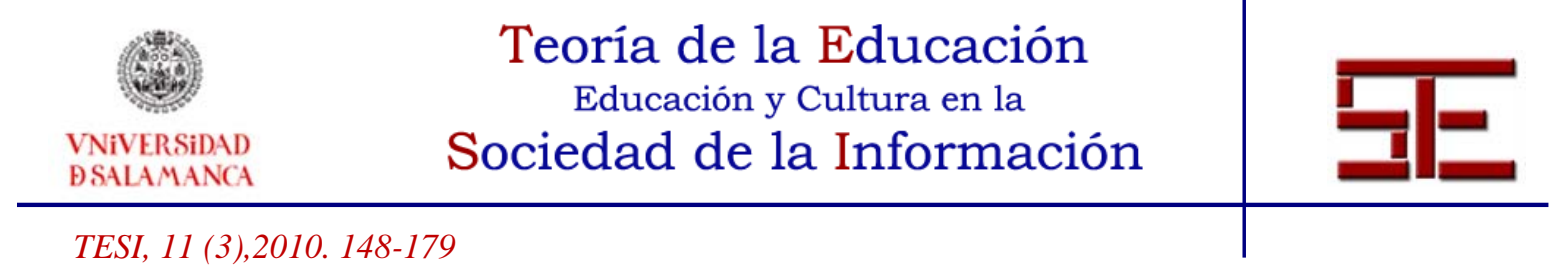

la Comunidad extremeña, determinando así los centros considerados de Buenas Prácticas con TIC.

La metodología llevada a cabo es de corte cualitativo, basado en el estudio de casos. La unidad de análisis es el centro educativo seleccionado como una institución que realizapotencialmente- Buenas Prácticas Educativas con TIC y, dentro de él, se definieron a su vez las subunidades de análisis, esto es: profesorado que ejecuta prácticas educativas TIC; Equipo Directivo; Alumnado con experiencia de aprendizaje con las TIC y Padres/Madres del alumnado con experiencia de aprendizaje con las TIC.

Según Vallés $(2003,100)$ el estudio de caso concentra diversas modalidades de investigación, a saber, los estudios etnográficos, biográficos y todos aquellos estudios caracterizados por una metodología singular o "que se encuentra a caballo entre lo cualitativo y lo cuantitativo". El estudio de caso desarrollado se sirve de diferentes técnicas de investigación. Utilizando la clasificación de las técnicas de investigación establecida por Vallés (2003), las técnicas de recogida de datos, entre otras, que nos han servido para la identificación de las Buenas Prácticas Educativas con TIC son:

a) De lectura y documentación:

- Recogida de material didáctico de elaboración propia y ajena. (ejercicios, tutoriales, referencia, simulación).

- Análisis de software educativo utilizado.

- Exploración de web/blog de docentes.

b) De observación y participación:

- Observación directa de sesiones de clases para su análisis posterior. El período de observación fue el que comprende una clase.

c) De conversación y narración:

- Análisis de entrevistas semiestructuradas efectuadas a distintos miembros de la Comunidad Educativa.

\section{5.- LA ORGANIZACIÓN DE LAS TIC DESDE LA PERSPECTIVA DE LOS COORDINADORES TIC, DOCENTES Y EQUIPOS DIRECTIVOS EXTREMEÑOS}

A continuación mostramos algunos resultados obtenidos de diversas entrevistas realizadas a distintos miembros de la Comunidad Educativa: representantes de Coordinadores/as TIC, Profesorado y Equipos Directivos. Y debido a que el tema que nos ocupa es lo relativo a aspectos organizativos de los centros de Primaria y Secundaria en la introducción de las TIC, nos centraremos en las manifestaciones de los

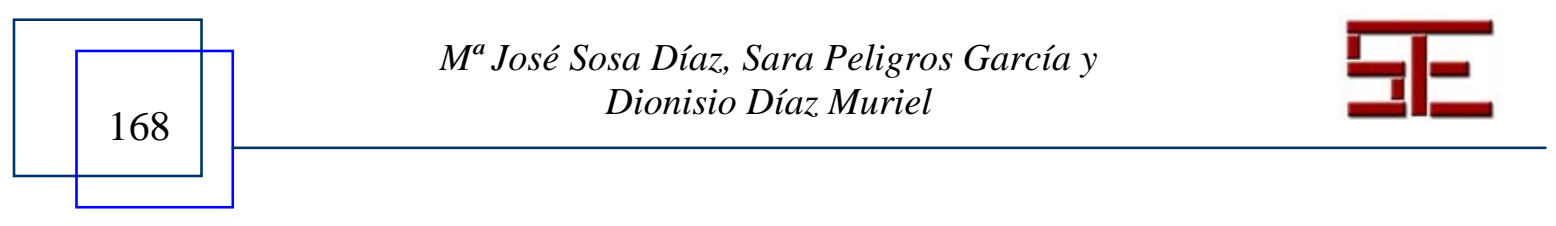




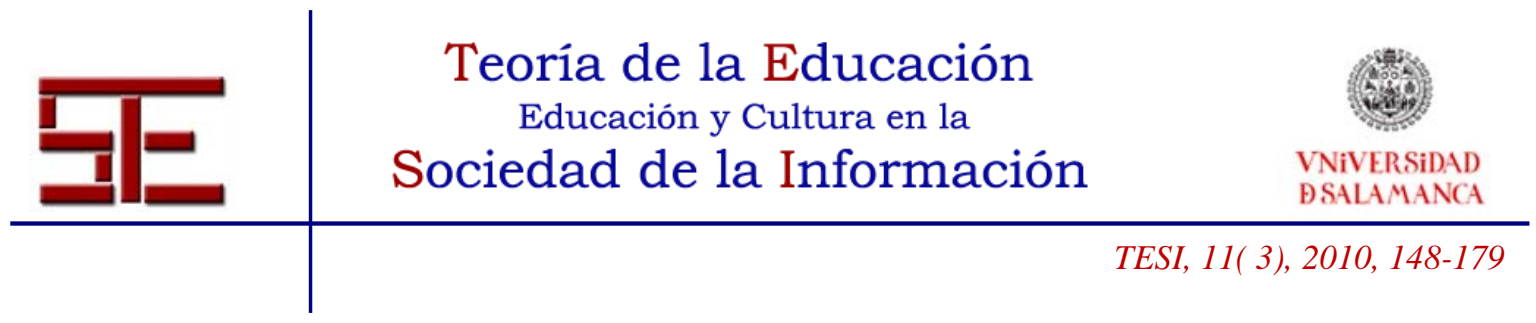

distintos agentes sobre dichos aspectos, relacionando esta información con los indicadores de Buenas Prácticas organizativas que habíamos reseñado en apartados anteriores.

Por un lado, la mayoría de las personas entrevistadas, Coordinadores/as TIC, profesorado y Equipos Directivos reconocen la importancia que tiene el uso de las TIC en la sociedad de hoy y consideran una buena iniciativa la política educativa que ha llevado a cabo la Administración en cuanto a la introducción de las tecnologías en los centros educativos.

"La Junta de Extremadura, yo creo que está haciendo unos esfuerzos bastante grandes en Educación, y sobre todo en Tecnologías Educativas. Y está dotando bien a los centros” (Maestro/a de Primaria).

“Apostar en TIC hasta morir” (Coordinador/a TIC de IES).

"Yo pienso también que es un recurso imprescindible en la sociedad en la que vivimos y la que le espera a nuestros alumnos" (Director/a de un CP).

Esta introducción masiva de los ordenadores en los centros educativos ha producido cambios en la organización tanto a nivel de centro como de las aulas.

En los Institutos de Educación Secundaria, a pesar de que reconocen como una ventaja el acceso a las tecnologías de forma inmediata sin tener que cambiar de clase, en muchas ocasiones tales transformaciones son percibidas como debilidades, y piensan que se debería haber dotado sólo algunas aulas y no todas:

"Entonces claro, como lo tienen en la clase a disposición, lo pueden hacer... Si los tuvieran en un aula donde tú tienes que coger un horario, y tienes que abrir o tienes que pedir y apuntarte, etc..." (Coordinador/a TIC de IES).

“La presencia del ordenador causa un trastorno en el aula” (Coordinador/a TIC de IES).

“Hay ordenadores suficientes, en ocasiones de sobra” (Coordinador/a TIC de IES).

Los mayores problemas que se señalan a nivel organizativo en el aula debido a la instalación de los equipos informáticos son:

- Las mesas fijas impiden ciertos agrupamientos, lo que determina la metodología que utiliza el profesor o profesora y condiciona el tipo de actividades a realizar.

"Y luego... que la distribución de aula, tal y como está hecha, con las mesas fijas a un determinado puesto, impide agrupamientos. Solamente se puede agrupar a los alumnos, en el mejor de los casos, de cuatro en cuatro y poniéndose al revés”. (Coordinador/a TIC de IES).

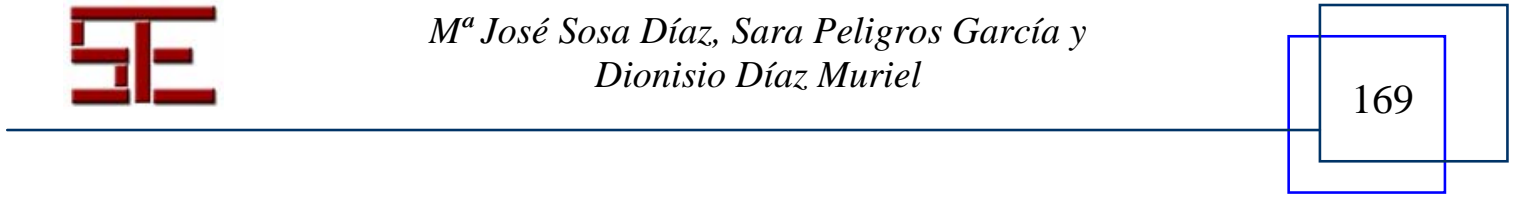




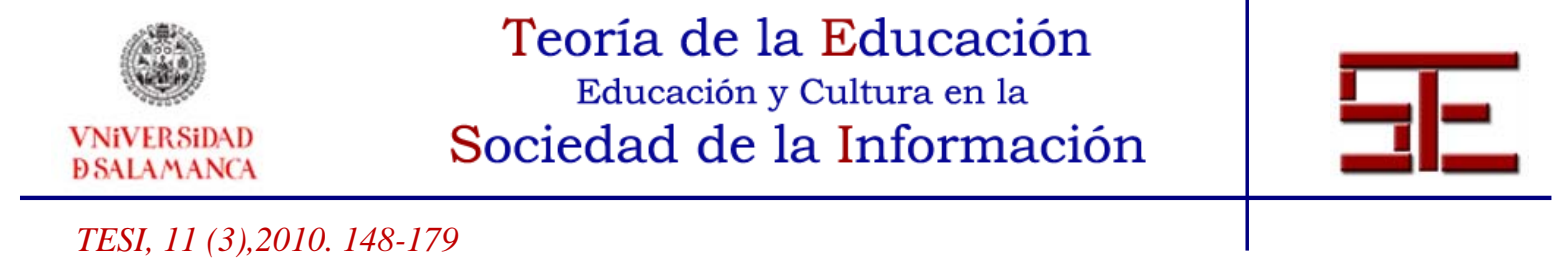

- $\quad$ Surgen problemas entre los estudiantes al tener que compartir el ordenador. Los alumnos y alumnas se interfieren en la búsqueda de información y hay disputas en cuanto a la utilización del equipo:

“Hay auténticas batallas entre los alumnos”. (Coordinador/a TIC de IES).

"A los alumnos les crea problemas porque uno tiene el ratón y otro el teclado. Y problemas de acondicionar, ¿no?”. (Coordinador/a TIC de IES).

- $\quad$ Muy a menudo fallan los equipos y esto ocasiona problemas a la hora de organizar la clase:

"El momento en que los enciendes.., hay cuatro ordenadores que te están fallando y no los puedes utilizar. Dime, ¿cómo acabas agrupando a los muchachos? Tienes que meter cuatro en un ordenador.” (Docente de TIC de IES).

- $\quad$ El tipo de mobiliario reduce el espacio de la mesa, los/as alumnos/as no pueden poner sus cosas y se ve reducida su visión de la pizarra. Además, éstos se esconden detrás del monitor y el profesor o profesora no puede controlar lo que hacen:

“Luego, te quita mucho espacio en las mesas. Los niños enredan mucho”. (Coordinador/a TIC de IES).

"La presencia de un monitor en medio de la mesa de un/a profesor/a en las aulas reduce la visión de la pizarra cuando estás exponiendo”. (Coordinador/a TIC de IES).

Sin embargo, los problemas organizativos que encuentran los docentes de los centros de Primaria son diferentes. En la mayoría de ellos han creado un horario de utilización de las aulas, de forma que se asignan a cada maestro o maestra las horas que puede hacer uso de algunas de las aulas de informática. Esto, por su parte, condiciona el uso de las tecnologías al momento que el maestro o maestra lo cree necesario, además de tener el inconveniente de cambiar de aula y movilizar al alumnado.

"Se percibe que aquí esto funciona y que se pueden manejar los ordenadores. Se utilizan. Tú tienes tu día ahí. Ya muchos días no tienes la hora ocupada y no puedes ir porque siempre hay gente. Si os fijáis es raro que el aula no esté funcionando, eso quiere decir que se mueve la cosa”. (Docente de CP).

Los Centros de Primaria e Infantil también se encuentran con problemas técnicos muy a menudo en sus aulas de informática, dificultando la organización durante la clase:

- $\quad$ Los equipos se albergan en aulas pequeñas y la distribución de los equipos no es la adecuada, lo que obstaculiza la atención y el aprendizaje del alumnado.

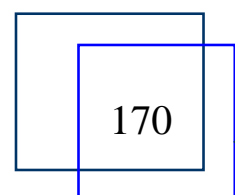

M José Sosa Díaz, Sara Peligros García y Dionisio Díaz Muriel 


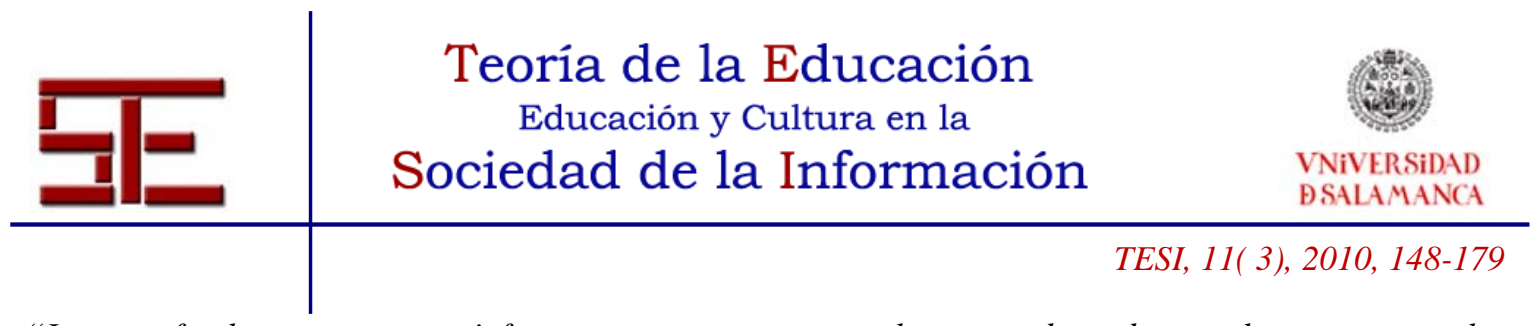

"Lo veo fatal, en cuanto a infraestructura no tenemos lugares adecuados en los que tener los ordenadores. El aula de informática es minúscula. Tenemos 20 ordenadores pero allí no caben 20 niños. Cuando podemos algunos cursos estamos desdoblándolos, y bajamos con la mitad, con 12, 14 alumnos, de esa manera intentamos trabajar con esa... Pero por lo demás es un aula muy poco amigable para estar ahí con más de 15”. (Coordinador/a TIC de CP).

- $\quad$ La Administración sólo tiene asignado un Técnico Informático por cada Centro de Profesores y Recursos, de manera que los centros deben esperar varias semanas para que se arreglen los equipos.

"Un administrador informático. Los institutos, los centros de Primaria uno por Centro de Profesores. Es que es en todo. [...] Mañana vengo a daros la solución, [...] y mañana y no ha venido todavía el chaval. Está hasta aqui”. (Secretario/a de CP).

Un agente importante para el uso de las tecnologías en el Centro es el/la coordinador/a TIC, y así lo reconocen tanto docentes como miembros del Equipo Directivo. Especialmente en los centros de Secundaria, el responsable de la Coordinación de las TIC es ayudado en sus funciones por el Administrador Informático pero, en todo caso, él o ella es sobre quien recae el fomento del uso de las Tecnologías de la Información y la Comunicación entre el profesorado. Incluso, frecuentemente, el Equipo Directivo relega a esta figura sus funciones en materia de tecnologías. Algunas de las tareas más importantes que realiza son, por un lado, coordinar y apoyar al profesorado, y, por otro, organizar y gestionar los recursos tecnológicos.

"El compañero Pedro (Coordinador/a TIC) es un entendido y no hay ningún problema. En cuanto le pides algo, él colabora para que se lleve a cabo”. (Docente de CP).

"Pero es porque hay un elemento que ha venido que sabe, pero que tampoco es su función específica esa, aunque ahora sea, digamos, el representante o Coordinador de Recursos TIC del centro, pero no es su función esa. Sin embargo, porque él es como es, nos transmite eso, y los demás podemos aprender". (Docente de CP).

"Y con la creación de estas figuras que os digo del programador informático y el Coordinador, para hacerle llegar a los profesores nuevos programas, nuevas opciones, nuevos caminos que..., que indagar en el mundo de las TIC ¿no?”. (Director/a de IES).

Aunque el tiempo y la poca liberación horaria son factores que impiden en muchas ocasiones a los/as coordinadores/as TIC poder realizar todas sus funciones, tal como nos comentan:

“No tengo tiempo para ayudar a mis compañeros”. (Coordinador/a TIC de IES).

“No tengo tiempo de actualizar la página web”. (Coordinador/a TIC de IES).

“Entre otras cosas porque no tenemos más tiempo, es que..., muchas veces dices..., es que no tengo más tiempo, es que de mi tiempo también me gusta hacer otras cosas, mantiene portales, mantiene Rayuela,

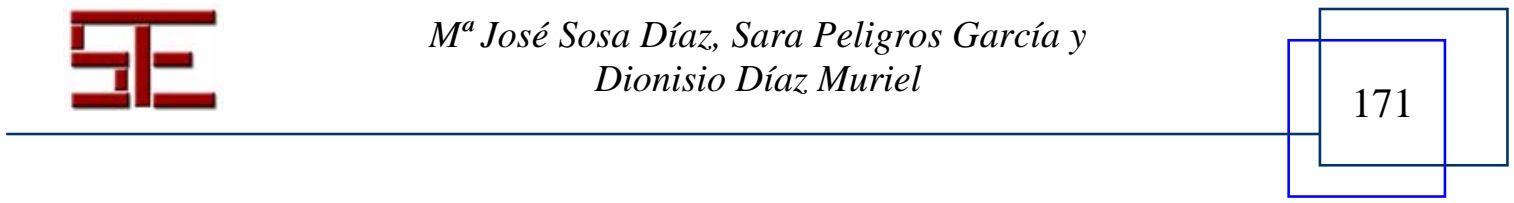




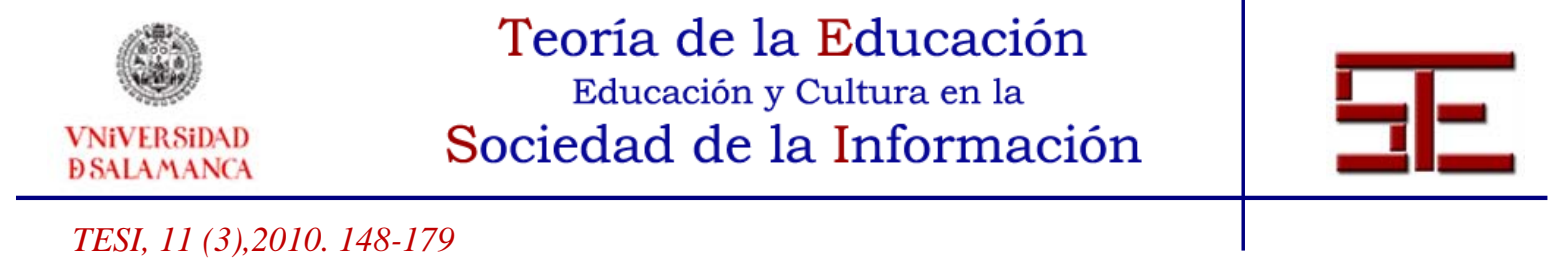

mantiene los equipos, mantiene la pizarra, diseña actividades, coordina actividades, y encima atiende a padres, atiende a niños, corrige exámenes, etc”. (Coordinador/a TIC y Director/a de CP).

En cuanto a la actuación del Equipo Directivo, a pesar de que en la mayoría de los centros su implicación en la integración de las tecnologías a veces no es la deseada, de que releguen sus funciones al coordinador/a TIC en este asunto, y que no nos consta que fomenten la creación de grupos de trabajo y colaboración entre los docentes, el apoyo que mantienen a los y las coordinadores/as TIC y a otros docentes comprometidos con las tecnologías es total, facilitando su labor.

"El Equipo Directivo está totalmente volcado, de que nosotros aquí trabajemos, no pone ningún obstáculo, al contrario, facilita totalmente la labor. Esperemos que sigan por muchos años". (Coordinador/a de CP).

Con respecto a la utilización de programas que favorecen la comunicación entre todos los miembros de la comunidad educativa y que permiten una gestión, administración y organización del centro de forma sencilla y rápida, como en apartados anteriores hemos mencionado, destaca el programa Rayuela, creado por la Administración. Los Equipos Directivos reconocen que, a pesar de los inconvenientes surgidos y la desconfianza en su puesta en marcha, es una herramienta muy útil para la gestión del Centro, que elimina papeleos y mejora las comunicaciones tanto con la Administración como con las familias. Así pues, Equipos Directivos, docentes y coordinadores/as TIC realizan una valoración muy satisfactoria de la plataforma.

"Y la verdad que a día de hoy entiendo que es una herramienta muy útil para la gestión de los centros, muy útil, intuitiva, sencilla, simplifica mucho y nos quita mucho trabajo”. (Coordinador/a TIC y Director de CP).

“No nos fiábamos mucho de Rayuela en un principio”. (Director/a de CP).

“A ver..., al principio de curso ha sido atacante”. (Secretario/a de CP).

"Yo creo que sí, que el futuro. Vamos... cuando esté en pleno funcionamiento en todos los aspectos de gestión del centro tiene que evitar mucho papeleo”. (Director/a de CP).

"El grado de satisfacción es bueno porque ven eso una ventaja, es decir, esa plataforma va a ser magnífica porque date cuenta que es algo que ha empezado, digamos, dando los primeros pasos en ello ¿no? Pero que va a ser algo espléndido y los profesores ven sus ventajas, claro”. (Director/a de IES).

Sin embargo, la Dirección también confiesa que todavía la plataforma está infrautilizada. Por un lado, algunas funciones sobre gestión del centro aún no se utilizan. Y por otro, a pesar de que la mayoría de los docentes manejan Rayuela, sólo utilizan las funciones obligatorias como son la del control de faltas y la de evaluación,

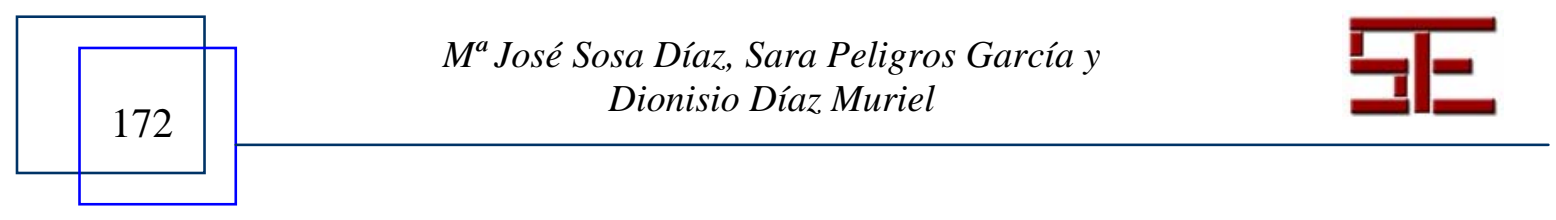




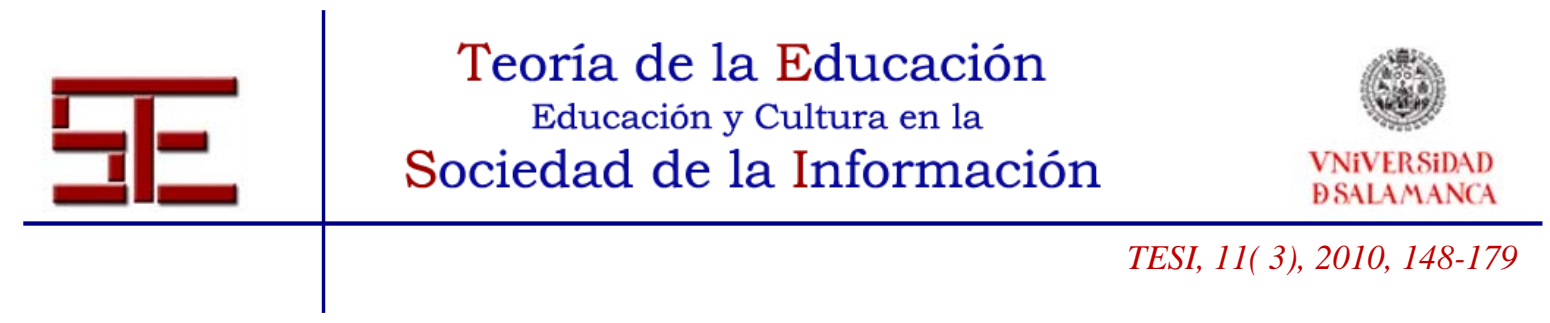

siendo pocos los docentes que la usan como medio de comunicación con los padres y madres.

"Y luego, por último, sería otro objetivo, utilizar las TIC como recurso para la organización, gestión y administración del centro. Ahora con lo de Rayuela, antes era con el Programa Escuela.., pero este verano ya matriculamos a todos los alumnos. Ya tenemos la evaluación, luego ya está previsto este año la escolarización y demás. Toda la organización y gestión también”. (Director/a de CP)

"Rayuela no es solamente control de faltas y poner notas. Tienes tu asignación de tareas, tus controles, tu mensajería con los padres, los padres contigo, todo eso prácticamente no se ha utilizado". (Coordinador/a TIC y Director/a de CP).

"Esto de Rayuela es estar al 100\%.., que hay uno o dos casos. Pero las notas si se están poniendo". (Miembro del Equipo Directivo de IES).

Una función que se valora positivamente de Rayuela es la comunicación con otros miembros de la comunidad educativa y, aunque todavía no se utilice en gran medida, se establece como objetivo a conseguir. Señalan que el uso por parte de las familias del programa Rayuela va en aumento y que una de las dificultades que los docentes encuentran para establecer comunicación a través de Rayuela con los padres y madres en muchas ocasiones es debido a la falta de formación y recursos de éstos.

"Otro objetivo sería fomentar el uso de las TIC como medio de comunicación entre los agentes implicados entre profesorado, padres y Administración. Eso se favorece con Rayuela". (Director/a de $\mathrm{CP})$.

"Y luego nosotros con la Administración, pues nos comunicamos a través de Rayuela, y por correo electrónico [...]”. (Director/a de CP).

"Comunicación tutores-padres no, pero sí me consta que los padres entran en Rayuela porque muchas veces vienen y te comentan y te dicen <<oye que no veo a mi niño>>, y resulta que es que hay algún dato que hay mal puesto". (Coordinador/a TIC y Director/a de CP).

"No todas las familias tienen un ordenador". (Director/a de IES).

Por último, en cuanto a los programas de gestión del aula como son ControlAula y AulaLinEx los docentes realizan una valoración muy positiva destacando las siguientes posibles funciones:

- $\quad$ Realizar presentaciones de contenidos y demostraciones didácticas.

“Usando el programa este..., el AulaLinex, uso mi..., enciendo mi ordenador. Lo hago yo. Pongo para que ellos vean lo que estoy haciendo yo. Hago una DEMO de cómo se hace una cosa”. (Docente de IES).

- $\quad$ Enviar y recoger materiales y documentos.

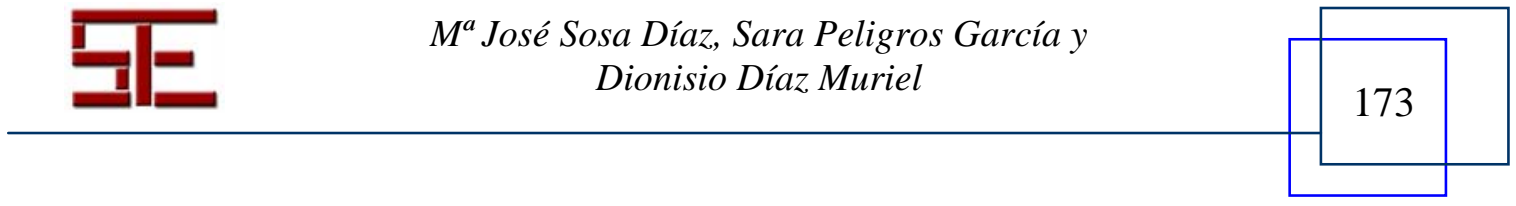




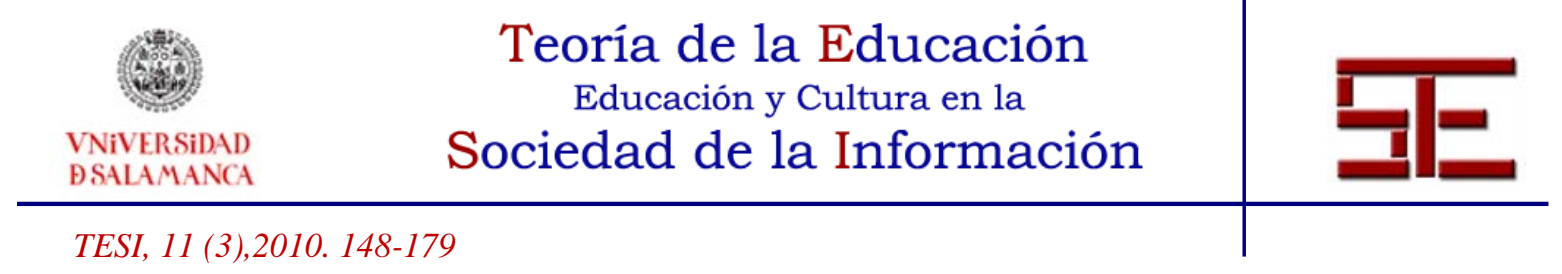

“Ellos suben sus materiales, pero bueno... Yo desde mi puesto de profesor puedo recogerlos ¿no? con el programa AulaLinEx”. (Docente de IES).

- Control del progreso del alumnado en el aprendizaje y atención a la diversidad.

"A través del ControlAula tú puedes estar viendo lo que está haciendo cada alumno, y puedes estar viendo, pero ahí, en esos momentos, no le tienes que pedir nada. Puedes estar viendo el desarrollo de su actividad y cómo está progresando. Puedes atender a la diversidad también de otra manera". (Docente de IES).

- $\quad$ Supervisión del comportamiento de cada estudiante

"Luego ellos hacen lo que les da la gana. Te cambian el fondo de escritorio, el salvapantallas, hacen desastres... Los chavales de las aulas Linex no pueden hacer nada de eso, si no tienen permiso no pueden hacer lo que tú no quieras que hagan, siempre que tú controles la aplicación. AulaLinex, se llama una, y ControlAula se llama la otra. Yo daría dinero por un ControlAula en mi clase, porque es que yo estoy dando clase y estoy escuchando con el teclado..., ¿qué están haciendo? Chateando”. (Coordinador/a TIC de IES).

\section{6.- CONCLUSIONES}

A la luz de las aportaciones detalladas a lo largo de este artículo, tenemos que considerar el esfuerzo económico efectuado por la Administración Autonómica Extremeña para dotar al Sistema Educativo regional de una infraestructura tecnológica. La adecuación de la arquitectura en los Centros de nueva construcción y la puesta en marcha de las distintas medidas de formación y fomento del uso de las TIC dentro de todos los centros educativos, han constituido un primer elemento vertebrador de Buenas Prácticas educativas y organizacionales con las TIC, opinión que es compartida con gran parte de la Comunidad Educativa Extremeña. A pesar de las numerosas dificultades y quejas recogidas sobre las limitaciones de las medidas tomadas, la mayoría de los entrevistados para nuestro estudio la han reconocido como una buena iniciativa y son conscientes de la relevancia de las TIC en la sociedad de hoy, así como para la educación del mañana.

La introducción masiva de las TIC en los colegios e institutos ha provocado, ineludiblemente, cambios en las formas de organizar los centros y también las aulas. Con respecto al equipamiento de la red de ordenadores y/u otros medios tecnológicos (como las Pizarras Digitales Interactivas) los distintos miembros de la Comunidad Educativa Extremeña señalan numerosas ventajas e inconvenientes en cuanto a la organización del centro y del aula.

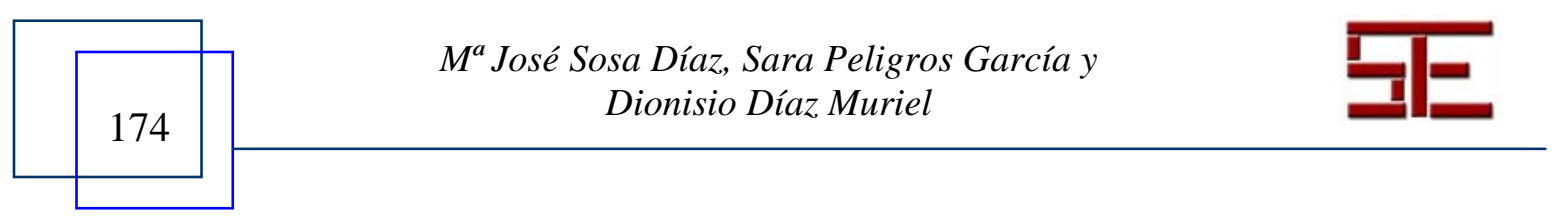




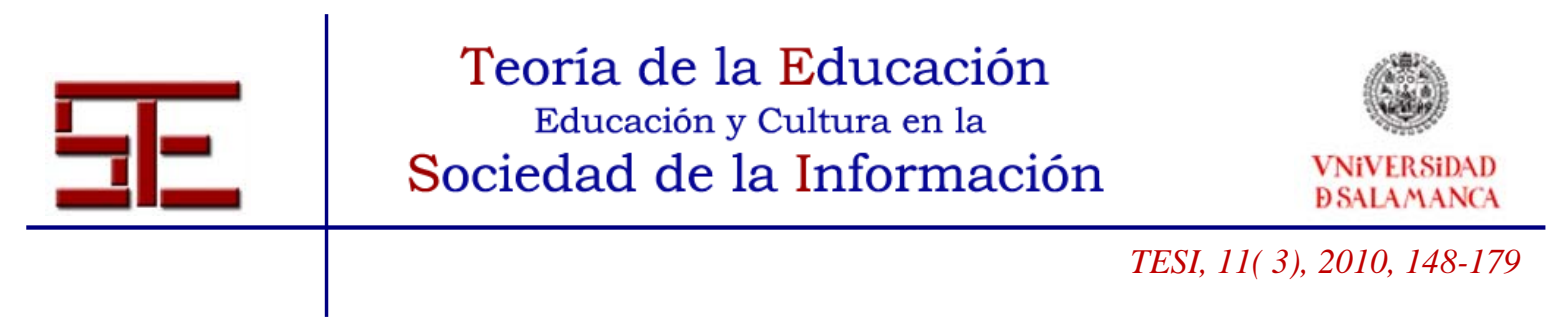

En primer lugar, la disposición de los equipos informáticos y otros dispositivos tecnológicos en todas las aulas de los centros de Educación Secundaria evita al profesorado alterar su programación en las respectivas Unidades Didácticas implementadas durante el horario lectivo, en cuanto se accede a los recursos informáticos en el lugar y momento que se precisan para impartir las clases. De hecho, ya no sería necesario reservar una hora específica, abandonar el aula y trasladar a los estudiantes a determinadas "salas" con ordenadores, cañones, etc., para enseñar contenidos concretos o ejecutar ciertas actividades contando con tales recursos de forma puntual. Esto permite al docente continuar con un orden lógico o secuencial su programación didáctica, aspecto que ha sido valorado positivamente por los profesionales entrevistados en el marco de nuestra investigación.

Este hecho no es percibido por todos los docentes de la misma manera y en ocasiones no están de acuerdo con la instalación masiva de los equipos informáticos en todas las aulas, ya que se encuentran con ciertos inconvenientes en la práctica de la docencia. La metodología didáctica se ve determinada por la disposición inflexible del mobiliario de la clase, organización que dificulta el trabajo en grupo, la discusión en clase y otras actividades que precisan agrupamientos diferentes del alumnado, como por ejemplo, una distribución en “U”. Además, los ordenadores instalados en las Aulas Tecnológicas son demasiado grandes, ocupando un gran espacio en la mesa de los/as alumnos/as, lo que reduce tanto el lugar de estudio como su visibilidad de la pizarra y el docente. Estas dificultades podrían ser mejoradas con disposiciones mucho más flexibles y otro tipo de elementos electrónicos como pantallas abatibles; equipos informáticos conectados en red de forma inalámbrica y que permitan mover las mesas; ordenadores más pequeños, a ser posible portátiles, de los que puedan hacer uso los estudiantes también en sus casas; entre otras soluciones.

Por su parte, el profesorado de los centros de Primaria e Infantil encuentra diversas trabas organizativas a la hora de utilizar las Aulas Tecnológicas y han procurado solventar estos inconvenientes estableciendo horarios donde se reparten el tiempo de uso de las aulas de informática, determinando de este modo el tiempo que el docente puede hacer uso de los múltiples contenidos y actividades que se desarrollan con los medios tecnológicos. Resultaría conveniente que en cada aula existiera un equipo informático conectado a un proyector o Pizarra Digital Interactiva, de forma que el docente tenga acceso inmediato a los contenidos que puedan ser requeridos en un momento concreto.

Esta introducción masiva de los ordenadores en las aulas presenta dificultades a la hora de resolver los problemas técnicos aparecidos. Con el fin de dar respuesta a tales inconvenientes, una de las medidas implantadas ha sido la creación de la figura del Administrador TIC o Programador Informático para los centros de Secundaria, y del

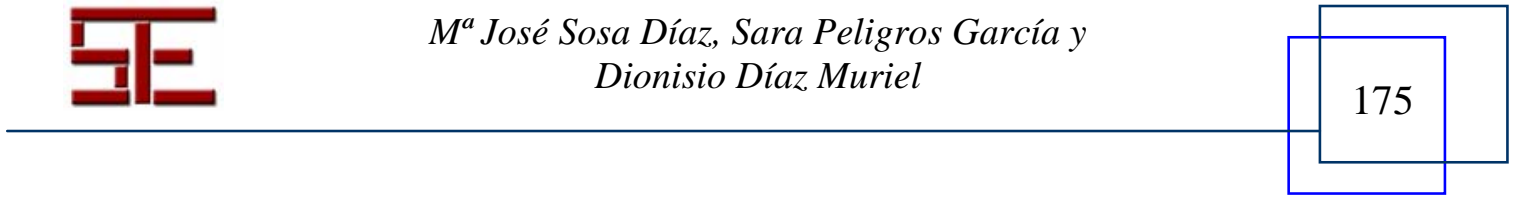




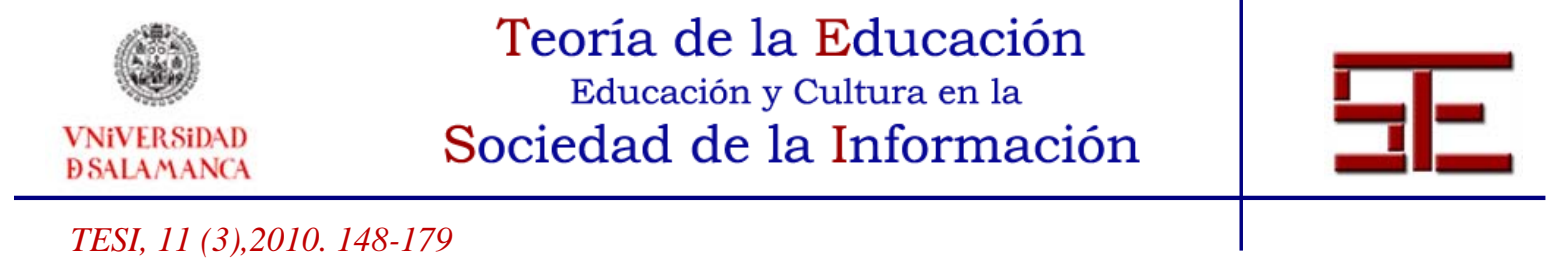

Técnico Informático ubicado en los CPR que asiste a los centros de Primaria e Infantil, quienes en calidad de asesores técnicos ayudan al mantenimiento y correcto funcionamiento de los equipos, facilitando a los/as profesores/as que exploten preferentemente su faceta docente y no tengan que convertirse por obligación en expertos informáticos ocupados en solventar problemas técnicos. Aunque es una medida considerada como Buena Práctica TIC, ésta puede llevarse más allá puesto que todavía hay docentes, sobre todo de Educación Infantil y Primaria, que denuncian la lentitud de la resolución de los problemas informáticos y las consecuencias que tiene esta situación para la organización y el desarrollo de sus clases. Es por ello que sería necesario aumentar el número de técnicos tanto en los colegios como en los institutos.

Un ejemplo de Buena Práctica educativa que recogeríamos desde el punto de vista del uso de las tecnologías lo representa la introducción de la figura del/la Coordinador/a TIC, y así lo reconocen miembros del claustro y Equipos Directivos. Justo este "experto docente” sirviendo de puente entre el Administrador TIC y el resto del profesorado, promueve una sinergia tendente a llevar a cabo medidas y prácticas pedagógica y didácticamente valiosas, en tanto en cuanto garantizaría una orientación a sus colegas sobre el manejo de los medios tecnológicos (según una visión puramente técnica), asesoraría en la utilización de los mismos en la dinámica habitual de las clases, esto es, con una finalidad educativa, y además se ocuparía de dinamizar el centro gestionando y coordinando todas aquellas actividades o proyectos que surjan relacionados con las tecnologías y la Educación. Sin embargo, muy a menudo los/as Coordinadores/as no disponen del tiempo suficiente para ocuparse de todas y cada una de las tareas encomendadas, y es por ello que no pueden realizar con total eficacia sus funciones. Sería muy recomendable que los/as Coordinadores/as gozaran de mayor liberación horaria, un mayor apoyo por parte de los Equipos Directivos (que no fuera simplemente "dejar hacer") y de mayor prestigio dentro del claustro. Siguiendo con la medidas adoptadas ya por otras Comunidades Autónomas, lo que sería mucho más eficaz y resolvería algunas de estas contrariedades es la creación de un Equipo TIC, formado por el/la Coordinador/a TIC, el Jefe o Jefa de Estudio o Director/a y un representante de cada ciclo. Este equipo puede aminorar la carga del Coordinador/a, obligaría al Equipo Directivo a implicarse totalmente en las decisiones que deben tomarse en materia de TIC dentro del centro, permitiría a los docentes colaborar de manera explícita para el uso de las TIC, y así cambiar la percepción de que es función única del Coordinador o Coordinadora. En definitiva, los planes estratégicos para la organización e introducción de las TIC dentro del centro serían mucho más democráticos, cercanos a la realidad, y se contaría con el apoyo y la colaboración de gran parte del claustro.

En global, y como consecuencia de la incorporación de estas figuras, la Buena Práctica educativa vendría potenciándose de manera que a todo el profesorado se le ofrece un apoyo profesional para la utilización de herramientas de gestión de aula y/o del centro

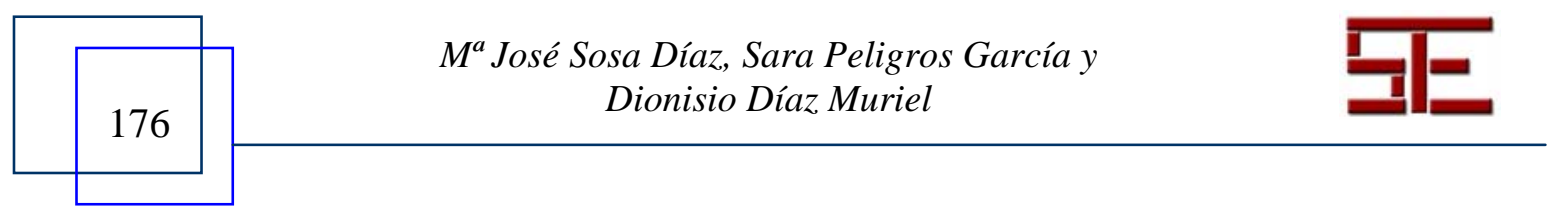




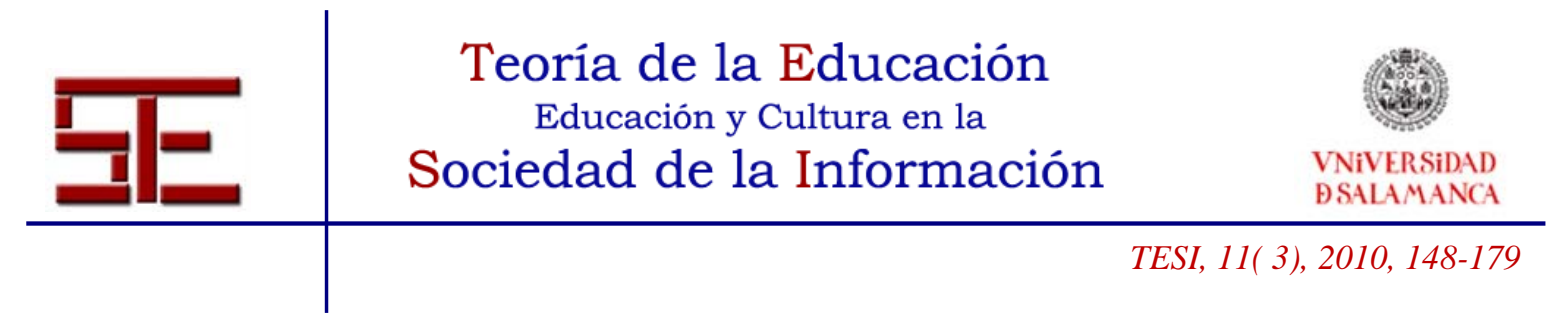

(Rayuela, ControlAula y AulaLinex) las cuales, a su vez, y a pesar de las dificultades y desconfianzas provocadas en un principio, han tenido una acogida grata por parte de docentes y Equipos Directivos. Estas herramientas poseen numerosas utilidades y a medida que va aumentando su uso mejoran poco a poco la gestión y comunicación de los centros en el caso de Rayuela, y el desarrollo de la docencia en el caso de ControlAula y AulaLinex. No obstante, es importante advertir que aún son infrautilizadas tanto por los docentes como por las familias y que no se conocen bien sus aplicaciones, por lo que es necesario que desde la Administración, y coordinado por el centro, se continúen tomando medidas de formación, facilidades e incentivos para el uso de éstas.

Por último, en lo que concierne a la planificación del uso de las TIC, constatamos que el hecho de describir en todos los documentos organizativos de centro tanto los medios y recursos como los modos en que se integrarán curricularmente las Tecnologías de la Información y la Comunicación en las diversas áreas, supone un esfuerzo por estructurar y delimitar didácticamente la práctica educativa con TIC. En efecto, desde las Programaciones de Aula hasta el Proyecto Educativo de Centro o la Memoria Final, deben aparecer reflejados los planteamientos sobre el uso que cada centro dará a las TIC, aspecto relevante de la integración real de la práctica educativa utilizando las TIC y que constituye una Buena Práctica de organización en sí mismo.

\section{7.- BIBLIOGRAFÍA}

Área Moreira, M. (2007). Algunos principios para el desarrollo de "Buenas Prácticas" pedagógicas con las TIC en el aula. Revista Comunicación y Pedagogía, 222, 42-47.

Bernal Bravo, C. y Rodríguez Fernández, A. (2007). La presentación de las prácticas docentes como vía para la integración curricular de los recursos digitales y el desarrollo profesional. Revista Comunicación y Pedagogía, 222, 66-71.

Casanova Correa, J. (2007). Desafíos a la formación inicial del profesorado: Buenas Prácticas educativas en el contexto de la innovación con TIC. Revista Latinoamericana de Tecnología Educativa, 6 (2), 109-125. Disponible en: http://campusvirtual.unex.es/cala/editio/.

Chickering, A.W. Y Eherman, S. (1996). Implementing the seven principles. Tecnology as lever. AAHE Bulletin, 3-6. Disponible en: http://www.tltgroup.org/programs/seven.html.

De Pablos, J. Y González, T. (2007, marzo). Políticas educativas e innovación educativa apoyadas en TIC: Sus desarrollos en el ámbito autonómico. Ponencia presentada a las II Jornadas Internacionales sobre Políticas Educativas para la Sociedad del Conocimiento, Granada.

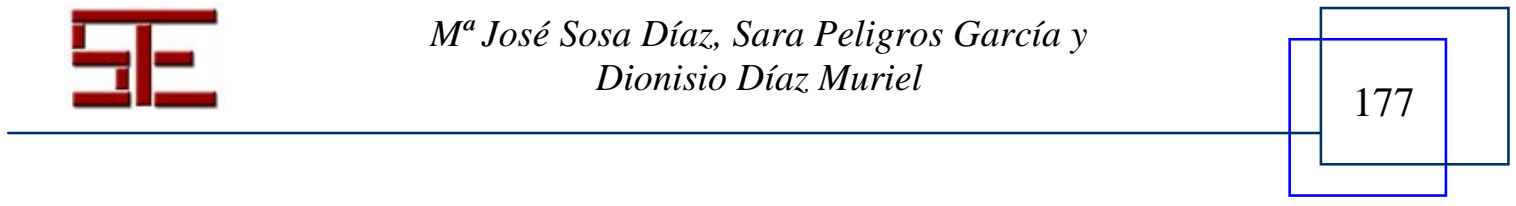




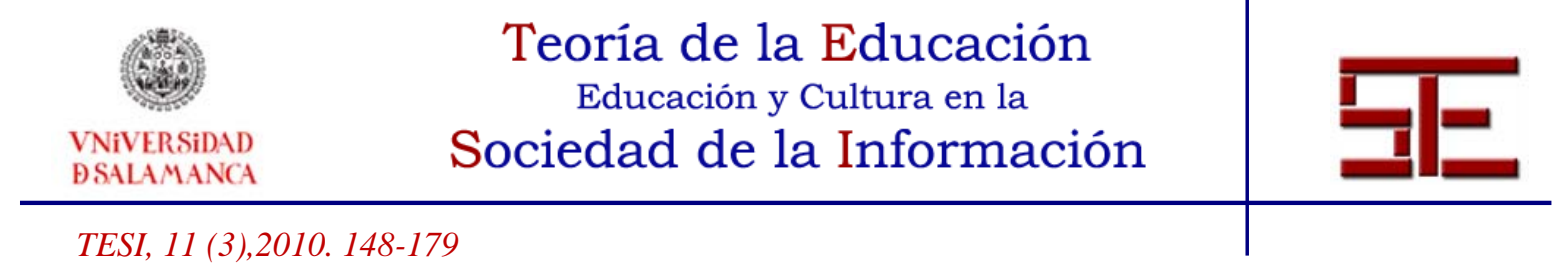

Díaz, D. (2004): La integración de las TIC en la educación formal: Red Tecnológica Educativa de Extremadura y GNU-Linex. Revista Latinoamericana de Tecnología Educativa, 3 (1), 45-66. Disponible en: http://campusvirtual.unex.es/cala/editio/index.php?journal=relatec\&page=article \&op=viewFile\&path[]=22\&path[]=19.

Dulac, J. (2004). Referencial de Buenas Prácticas para el uso de las TIC en los centros educativos. Disponible en: http://www.isftic.mepsyd.es/w3/cinterneteducacion/2congreso_actas/documentos/experiencias/pdf/foro1/Jose_Dulac_Referencial_de _buenas_practicas_para_el_uso_de_las_TICs.pdf.

(2004). La pizarra digital: la dirección de los centros educativos ante el reto tecnológico. En Villa Sánchez, A. (coord.) Dirección para la innovación: apertura de los centros a la sociedad del conocimiento, Bilbao: Universidad de Deusto. (pp. 673-688).

Epper, R. Y Bates, A. W. (2004). Enseñar al profesorado cómo utilizar la tecnología. Buenas Prácticas de instituciones líderes. Barcelona: Editorial UOC.

Garrido, M. C., Fernández, R. y Sosa, M. J. (2008). Los Coordinadores TIC en Extremadura. Análisis legislativo y valoración de su implantación en los centros educativos de primaria y secundaria de la región. Ponencia presentada en el Congreso Virtual Educa 2008.

Instrucciones de 27 de junio de 2006, de la Dirección General de Política Educativa por la que se concretan las normas de carácter general a las que deben adecuar su organización y funcionamiento las Escuelas Infantiles, los Colegios de Educación Primaria, los Colegios de Educación Infantil y Primaria y los Centros de Educación Especial de Extremadura.

Instrucciones de 7 de julio de 2004, de la Secretaría General de Educación, por la que se concretan las normas de carácter general a las que deben adecuar su organización y funcionamiento los Centros de Educación Secundaria dependientes de la Consejería de Educación, Ciencia y Tecnología.

Marqués, P. (2002). Buenas Prácticas docentes. Disponible en: http://dewey.uab.es/pmarques/bpracti.htm.

Palomo, R., Ruiz, J. Y Sánchez, J. (2006). Las TIC como agente de innovación educativa. Sevilla: Consejería de Educación de la Junta de Andalucía. Disponible en: http://www.juntadeandalucia.es/averroes/publicaciones/nntt/TIC_como_agentes innovacion.pdf .

Valverde Berrocoso, J. (2007). El software libre y las "Buenas Prácticas" educativas con TIC. Revista Comunicación y Pedagogía, 222, 48-55.

Valverde, J., Díaz, D., Garrido, M.C., López, E. y Fernández, R. (2007). Modelo organizativo para el uso educativo de las TIC en Extremadura. Ponencia presentada en el I Congreso Internacional Escuela y TIC. IV Forum Novadors.

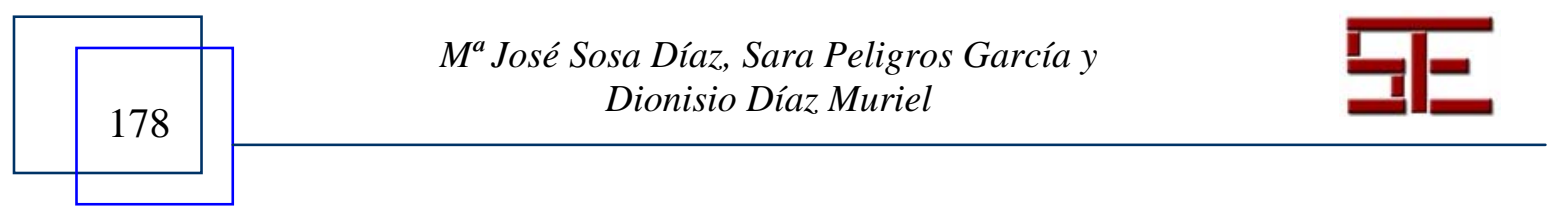




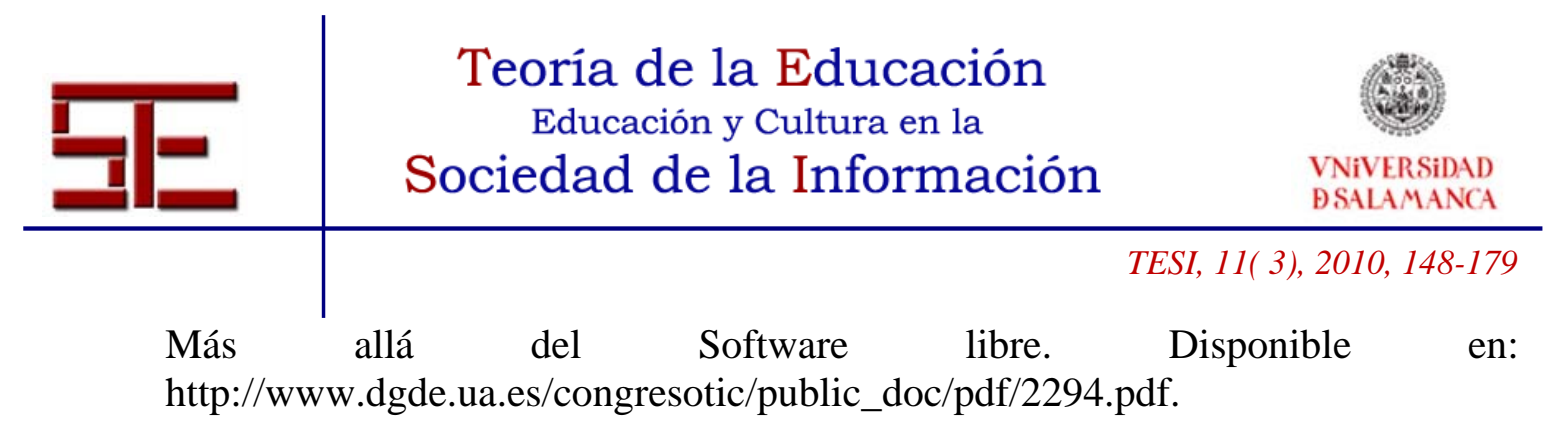

${ }^{1}$ La investigación que ha servido de base para este artículo, “Análisis de las políticas educativas para la integración y uso de las TIC en el sistema educativo de Extremadura y sus efectos en la innovación didáctica.”, ha sido financiada por el Ministerio de Ciencia e Innovación. Dirección General de Programas y Transferencia del Conocimiento. Plan Nacional de I+D+I 2006-2009. Ref. SEJ2006-12435-C0505/EDUC. Llevada a cabo por el grupo de investigación reconocido “Nodo Educativo”, del cual es director Jesús Valverde Berrocoso.

Para citar el presente artículo puede utilizar la siguiente referencia:

Sosa Díaz, Mª J., Peligros García, S. y Díaz Muriel, D.: (2010). “Buenas prácticas organizativas para la integración de las TIC en el sistema educativo extremeño”. En De Pablos Pons, J. (Coord.) Buenas prácticas de enseñanza con TIC [monográfico en línea]. Revista Electrónica Teoría de la Educación: Educación y Cultura en la Sociedad de la Información. Vol. 11, nº 1. Universidad de Salamanca, pp. 148-179. [Fecha de consulta: $\mathrm{dd} / \mathrm{mm} / \mathrm{aaaa}]$.

http://revistatesi.usal.es/ revistas_trabajo/index.php/revistatesi/article/view/5839/5865 ISSN: 1138-9737

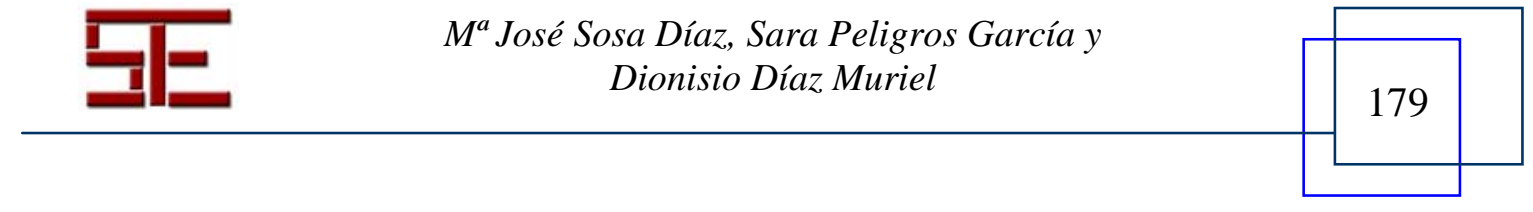

